\title{
توظيف الإتجاهات هتعددة الأغراض بالموضة فى إعادة تدوير الملابس المستعملة
}

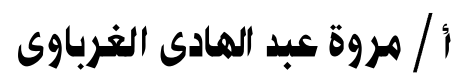

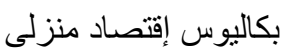

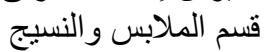

كلية الإقتصاد المنزلي - جامعة المنوفية

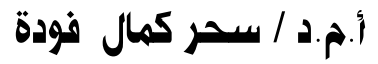

أستاذ مساعد بقسم ملابس و النسيج كلية الإقتصاد المنزلي مابني

جامعة المنوفية
أ.دة/ هدي هحمد سامي غازي

أستاذ تصميم الأزياء قسم الملابس و النسيج الإنجياء كلية الإقتصاد المنزلي لئي جامعة المنوفية

\section{ملخص البحث}

ظهر فى الأونه الأخيرة فن التدوير و إعادة إستغلال كل الأشياء وتدويرها مرة أخرب لمحافظة على البيئة وشمل ذلك إعادة تدوير الملابس نظر الإستهلاك البشر لكميات هائلة من الملابس وفى هذا المجال تعرضت العديد من الدراسات التطبيقية للإستغلال الأمتل والمفيد فى إعاده التذوير بقايا الاقمشه و الملابس المستعملة لتحويلها الى منتج جديد بأغراض وظيفية جديدة نافعه وبشكل إقتصادي ولذلك يهدف البحث الى إعادة تدوير البنطلون الحريمى بأشكالة وخاماتة المختلفة لعمل تصميمات مستحدثة مسايرة لروح الموضة المعاصرة وذلك بإستخدام إتجاة جديد فى الموضة وهو الموضة متعددة الأغر اض بحيث تكون القطعة اللملبسية الواحدة لها أكثر من إستخدام وظيفى مما يعمل على رفع القيمة الجمالية والإقتصادية للقطعة الملبسية الواحدة من خلال إعادة التدوير وتعدد إلمد الجو انب الوظيفية للقطعة وذلك بإستخدام الكلف و المكملات مع مر اعاة أسس وعناصر التصميم وتحقيق القيم الجمالية و الوظيفية.

وقد تم إعادة تدوير عدد ابنطلون حريمى من خامات مختلفة (الجينز _الفسكوز _الليكرا) وعمل كلم عدد من تصميمات نتتوع بين الجونلة والبلوزة و الثنطة و الكاب الحريمى من كل بنطلون وتم إستطلاع أراءالمتخصيصين فى مجال الملابس والنسيج من خلال إستمارة إستبيان تحتوى على اربع محاور مختلفة وهى ( تحقق عناصر التصميم - تحقق أسس التصميم -تحقق الأبتكار و التميز -تحقق الجانب الوظيفى ) فى إستخدام الموضة متعددة الأغراض فى إعادة تدوير البنطلون الحريمى و أظهرت النتائج نجاح التصميمات المنفذة فى تقديم تصميمات مبتكرة مسايرة للموضة يمكن إرتدائها بعدة طرق مختلفة ويوصى البحث بتطبيق إتجاة الموضة متعددة الأغر اض فى إعادة تدوير الملابس و المفروشات وجعلها نو اة لصناعات صغيرة.

\section{key words - الكلمات الإنتاحية}

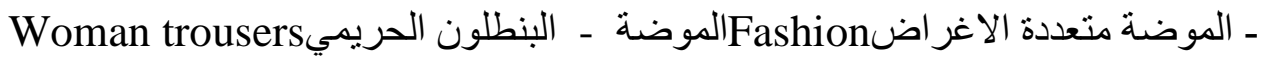
Fashion Multifunction إعادة التدوير - recycling 


\section{Employment the multi-purpose trend of fashion to Recycling second - hand clothes}

\section{$\underline{\text { Abstract }}$}

Recently, the art of recycling and re-exploitation all things has emerged in order to preserve the environment, including the recycling of clothing due to the consumption of huge quantities of clothing by humans, and in this area, several applied studies have been addressed to the optimal and the useful exploitation in the recycling of fabrics remnants and second-hand clothes to convert them to new and useful product with new functional and economical purposes. Therefore, the research aims to recycle women's trousers with its different types and materials to create new designs in keeping with the contemporary fashion spirit by using a new trend in fashion. This, is the multipurpose fashion so that the single piece of clothing has more than one functional purpose, thus increasing the artistic and economic value of the single piece by restoring Rotation and multi-functional aspects of the piece using the sewing and supplements, taking into account the basics and elements of design and achieve aesthetic and functional values.

6 women's trousers were recycled from different materials (jeans, viscose and lycra). A number of designs were made, ranging from skirt, blouse, pouch, and cap from each trouser. The opinions of specialists in the field of clothing and textiles were surveyed through a questionnaire containing four different axes. (Check the design elements - check the foundations of design - achieve innovation and excellence - achieve the functional aspect) in the use of multi-purpose fashion in the recycling of women's trousers, the results showed the success of the designs implemented in the presentation of creative designs compatible with the fashion, that can be worn in several different ways. The Research recommends the applying of the multi-purpose trend of fashion in the recycling of clothing, furnishings and making them the nucleus of small industries.

\section{Key words}

Women trousers - Fashion - Multi-purpose Fashion - Recycling 


\section{المقدمة المة}

تعكس الموضة النطورات والأحداث الجارية حول العالم بصفة عامة وداخل الكثير من المدن المهتمة بصناعة الموضة بصفة خاصة كما أنها تعبر عن الافكار التى يشترك فيها لهانها عدد من الناس فى أى وقت من الأوقات سواء كانت فى الأزياء او الأثاث اوالعمارة

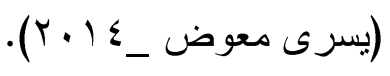

وتو اجهة الموضة العديد من التحديات البئية وذلك لعدة اسباب منها عو ادم ومخلفات صناعة

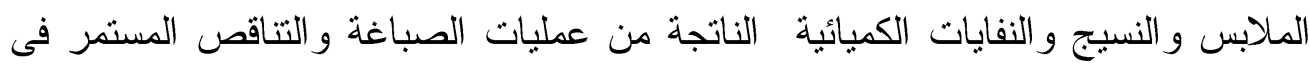

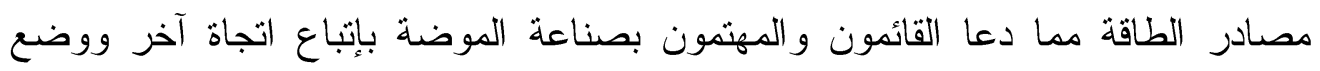

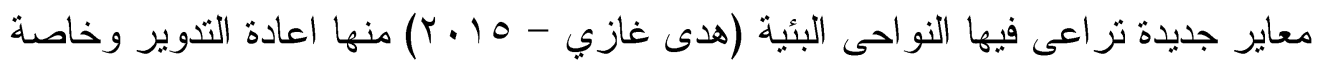
للملابس نظر الاستهلاك كميات هائلة من الملابس وظهر في هذا المجال اتجاهين اساسيين

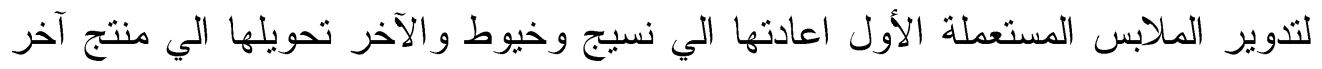
ذو غرض وظيفي وجمالي مختلف. ومن هنا تتلخص مشكلة البحث فى الإجابة على التساؤلات الاتية:-

• ما الإستفادة من الموضة المتعددة الأغر اض في إعاده تدوير البنطلون الحريمى ؟

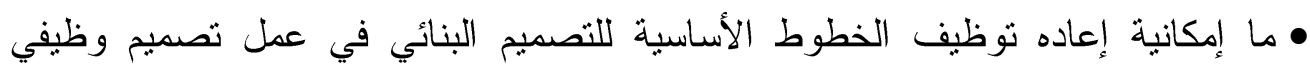

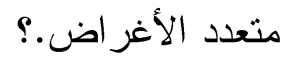

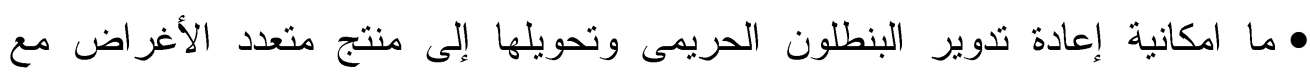
مر اعاه القيم الجمالية و الوظيفية ؟ الواده Objectives أهداف البـــثم • إعادة تدوير البنطلون الحريمى وتحويله إلي منتجات متعددة الأغراض بشكل جديد مساير للموضة. • رفع القيمة الجمالية و الوظيفية للبنطلون الحريمى بتحويله إلي منتجات متعددة الأغر اض. • الأستفادة من جماليات مكملات الملابس المنصلة لرفع القيمة الجماليةو الوظفية للبنطلون لإنهات

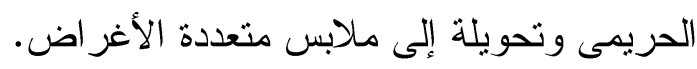
Significance أهـمية البحث ونحوبه • إعاده تدوير البنطلون الحريمى لإنتاج منتجات متعددة الأغر اض مسايرة للموضة تراعى له الناحية الجمالية و الوظيفية. 
• نوفير ميزانية الأسرة المخصصة للملابس باعادة تدوير الملابس المستعملة وتحويلها الي ملابس منعددة الأغر اض مسايرة للموضة. • إعطاء رؤية تصميمية جديدة ومختلفة لإعادة تدوير الملابس المستعملة. • التقليل من المخلفات و العو ادم كخطوة للمحافظة على البيئة.

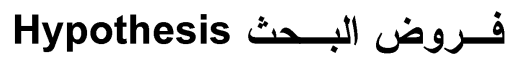

ا-يوجد فروق ذات دلالة إحصائية بين منوسطات أراء المحكمين على التصميمات المقترحة فى تحقق عناصر التصميم فى توظيف الموضة متعددة الاغر اض فى اعاد تدوير الملابس المستعملة ".

ץ-"يوجد فروق ذات دلالة إحصائية بين مثوسطات أراء المحكين على التصميمات المقترحة تحقيق أسس التصميم فى توظيف الموضة متعددة الاغر اض فى اعلى اعلد تدوير الملابس المستعملة"

ب-يوجد فروق ذات دلالة إحصائية بين منوسطات أراء المحكمين على التصميمات المقترحة تحقيق الجانب الابتكارى فى توظيف الموضة متعددة الاغر اض فى اعاد تدويز الملابس المستعملة " ع-يوجد فروق ذات دلالة إحصائية بين متوسطات أراء المحكمين على التصميمات المقترحة فى تحقق الجانب الوظيفى فى توظيف الموضة متعددة الاغر اض فى اعاد تدوير الملابس المستعملة". ه-يوجد فروق ذات دلالة إحصائية بين متوسطات أراء المحكمين على التصميمات المقترحة فى توظيف الموضة متعددة الاغر اض فى اعاد تدوير الملابس المستعملة".

Methodology منهج البحث مصدود البحث:البنطلون منهج نطبيقي تجريبي إعاده التدوير : هو إعادة استخدام المخلفات لإنتاج منتجات أخري أقل جودة من المنتج

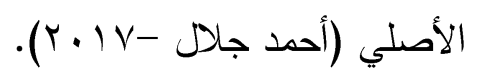

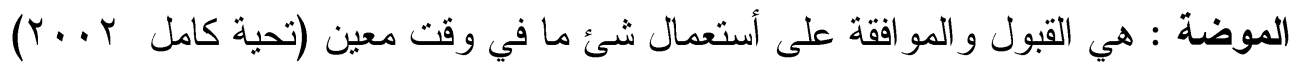


الملابس المتعددة الأغراض :- هى الملابس ذات الإستخدامات المتعددة تسمح الملابس ذات الإستخدامات المتعددة باستخدام القطعة الأساسية لأى ملبس و ابتكار الملبس من قطعة الإسنة ملبسية واحدة، فيمكنك الحصول على عدة أنثكال للملابس من قطعة ملبسية واحدة.(مى لإلى

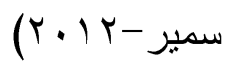
وتنقسم الار اسات السابقة على محورين :

المحور الأول الخاص بإعادة التدوير الملابس ( صناعة الملابس والنسيج ) )

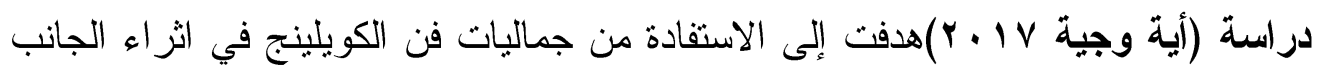
الجمالي و الوظيفي لملابس السيدات ومكملاتها .الحصول على تصميمات مبنكرة للمشغو لات الفنية المستخدمة في كلا من ملابس السيدات ومكملاتها باستخدام بقايا الاقمشة

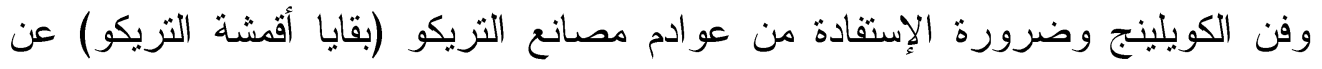
طريق إستخدامها في تزيين ملابس السيدات الخارجية وتوصلت الدراسة إلى انه توجد فروق ذات دلالة إحصائية في تحقيق ملاعمة استخدام فن الكويلينج في التصميمات المقترحة و في توظيف عناصر التصميم لتحقيق أسس التصميم للتصميمات المقترحة و تحقيق الجانب الابتكاري في التصميمات المقترحة

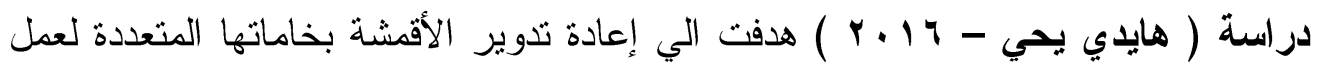

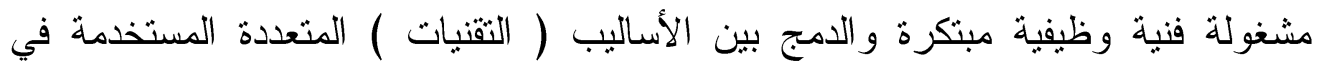

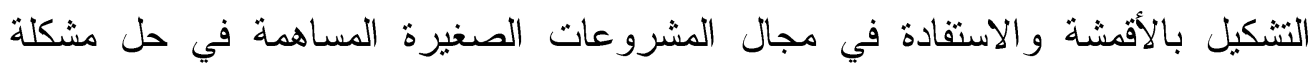
البطالة وخاصة لخريجي النزبية الفنية وتوصلت الي إمكانية و الاستفادة من مشغولات

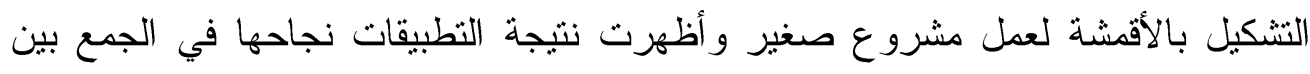
الجانبين الجمالي و الوظيفي واستيعاب القيم الجمالية من وحدة العمل الفني و التي نتجت عن

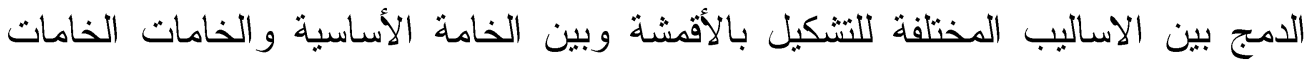
المساعدة ومر اعاة التو افق بينهم.

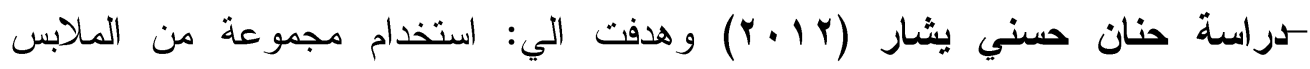
المستعملة (جونلة - بنطلون جينز - جاكت - بدي - عباءة) لانتاج حقائب السيدات يتنفيذ غرز تطريز باستخدام خرز بأحجام مختلفة . هوله 
وتوصلت الدر اسة الي : ضرورة استحداث حلول ابتكارية جديدة للملابس المستعملة و اعادة استخدامها مرة أخري فى صورة منتجات نفعية جديدة مما يؤدي إلى التوفير من الناحية

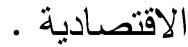

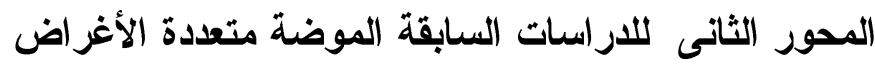

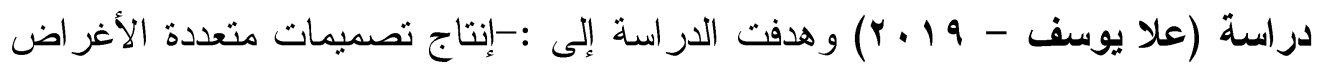
تصلح للفنبات في المرحلة الجامعية وذللك لإشباع حب التغيير و الظهور بمظاهر متعددة يتحقق فيها الجانب الجمالي و الوظيفي توصلت الدراسة الي انه يوجد فروق ذات دلالة إحصائية بين متوسطات أر اء المحكمين على التصميمات المقترحة في الملائمه للمرحله العمرية.

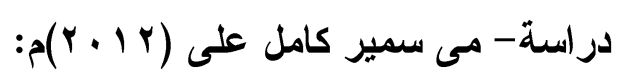

هدفت الدراسة الى - إلقاء الضوء على مفهوم القيمة المضافة في مجال تصميم الملابس

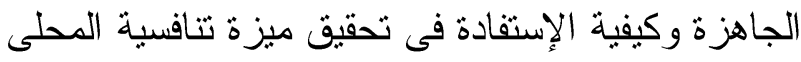
توصلت الدراسة - إيتكارتصميمات متعددة الاغراض ولكن مايميزها انها متعددة الاتجاهات فهو يمثل الاتجاة الاول وهو تعدد الاستخدام من خلال تعدد طرق الإرتداء

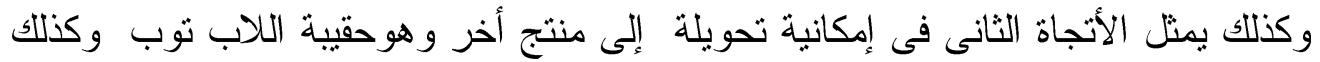

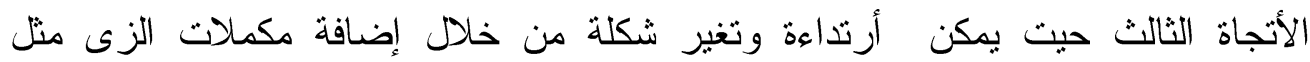
الإكسسواروهناك طرق لا حصر لها لتمثيل هذا الإتجاة لذلك وأهم ما يميز هذا التهيل التصميم هو إمكانية إرتداءة لكل من المحجبة و الغير محجبة

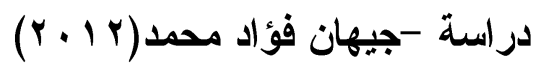

و هدفت الدراسة الى اقتر اح تصميمات ناجحة تحقق الأداء الوظيفى وتتميز بشكل جمالى مقبول تحقق هذة التصميمات الراحة والامان فى الإستخدام بجانب المتطلبات الإقتصادية

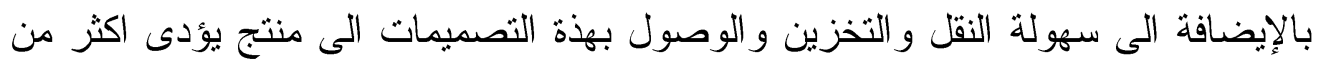
وظيفة وبجودة عالية مع تكلفة معقولة وتوصلت الى توجد علاقة ايجابية فى العلاقة السيكولوجية بين المنتج المتعدد الوظائف و المستخدم نجاح اسلوب الطى السريع و الذى يقوم المستخدم بفتحة واغلاقة بنفسة وبسرعة دون اى جهد مما يقوى العلاقة بين المستحدم و المنتج ويجعلة يشعر ان هذة المنتجات لم تعد عبه عليه. 


$$
\text { دراسة- ياسمين احمد محمود -( • ( ب)م: }
$$

هدفت الدراسة الي - امكانية نوفير ملابس متعددت الأستخدام تفي بالإحتياجات الملبسية

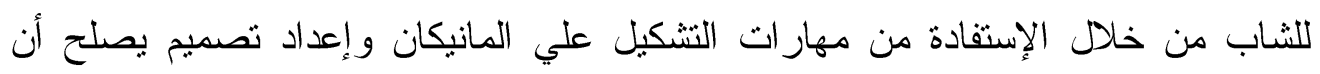
يرتدي باكثر من أسلوب لبعطي في كل مرة مظهر مختلف ومتجدد توصلت الدر اسة إلى: مهن

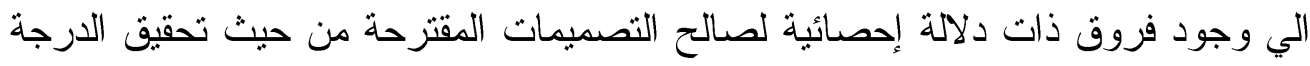
الأبتكارية المطلوبة، تحقيق أسس و عناصر التصميم، ملائمة التصميمات لإحنباجات الثباب الملبسية،ملائمة التصميمات لإسلوب النشكيل علي المانيكان، ملائمة النصميمات لمنطلبات السوق، الأستفادة من فن أختبار ملابسهن وتوصلت أن الأراء المتخصيصين كانت إيجابية

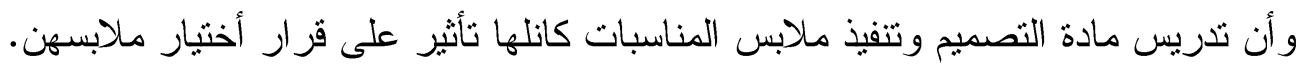

\section{الاطار النظرى Theoretical framework}

pants البنطلون

كلمة فرنسية تستخدم للالالة على ملبس خارجى يغطى الجزء الاسفل من الجسم يبدا من

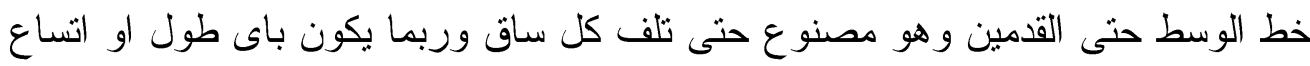

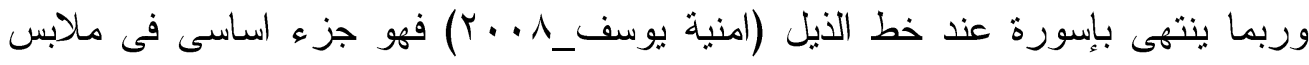

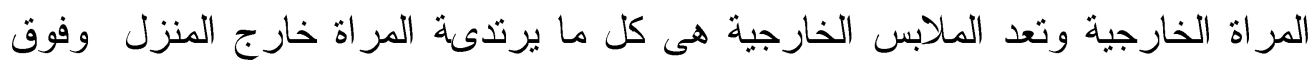

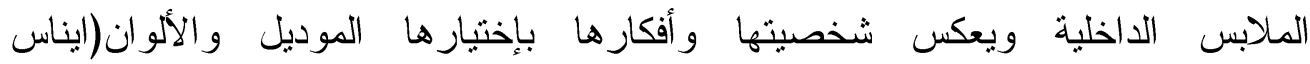
موسى_r ( • و) والجدير بالذكر ان البنطلون من اهم القطع الملبسية التى يمكن ارتداءها

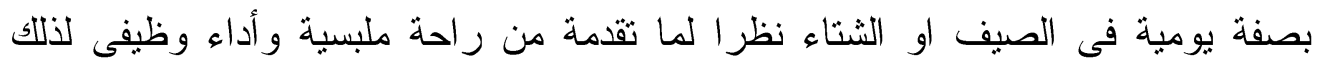
تكون من اهم القطع المستهلكة والتى تحتاج الى أعادة تدوير خاصة لما بها من اماكن

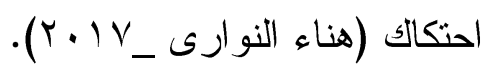

Accessories المكملات

تعرف مكملات على أنها قطع او أدوات تصاحب الملابس تعمل علي زيادة تأثثرها مما

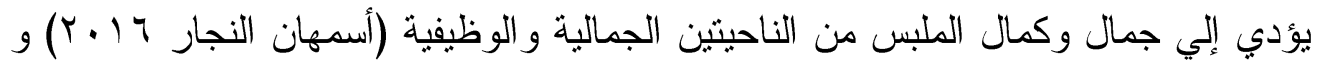
هى تلك اللمسة السحرية للموضة والتى تضيف إلى مظهر الثخص بريقا وجاذبية والتي بدونها لا يكتمل المظهر الخارجي للفرد لذا فهي تكون مبهجة مزينة وتضاعف فعلا من ثقة

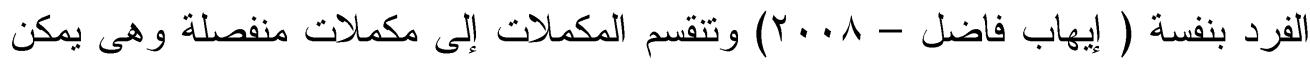
إضافتها او إزالتها عن الملابس دون الثأثثر على الملبس مثل (حقائب اليد -الاحزمة- 
القفازات -الإيشاربات ـالحلى الجوارب) اما المكملات المتصلة وهى المنصلة وثابتة مع الملبس و إز التها تسبب خلل لخطوط التصميم و الوظيفة مثل (السوست -الكبش-الأزرار -

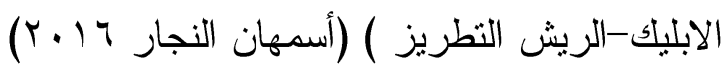

Recycling إعادة التدوير التدوير هوعملية إعادة تصنيع وإستخدام المخلفات سواء منزلية اوالصناعية او الزر اعية وذللك لتقليل تأثثر هذة المخلفات وتر اكمها على البيئة وتتم هذة العملية عن طريق تصنيف المخلفات على أساس المواد الخام الموجودة بها إعادة تصنيع كل على حدة (هدى غازى لهى

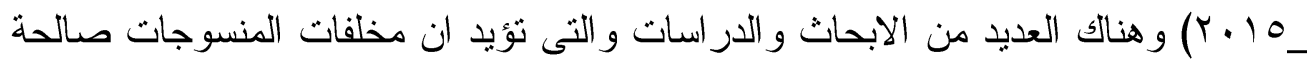
لاعادة التّوير و لا ينتج عنها مواد ضارة ويتم تجميع المخلفات الى مر اكز اعادة التنوير

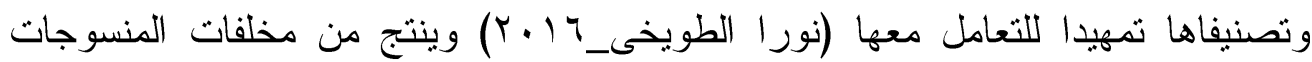
نسبة قليلة من المواد الصلبة و التى يتم اعاددة تدويرها الى منسوجات درجة تانية و التى لهى

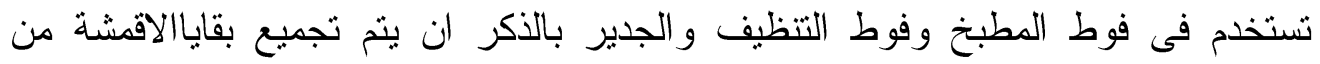

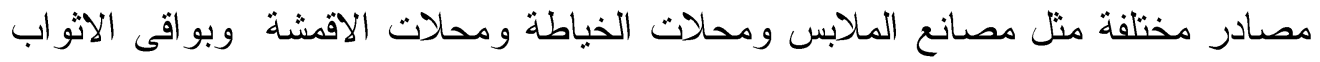
و التى تقل عن نصف مثر ولاتزيد عن مثرين ونصف وذللك لاعادة استخدامها فى

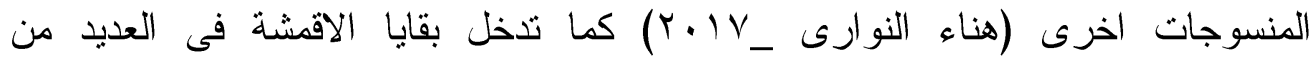

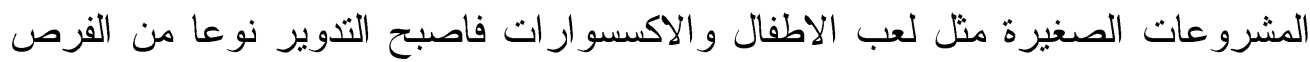

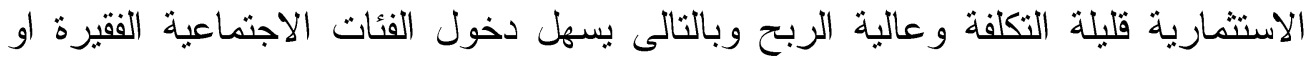

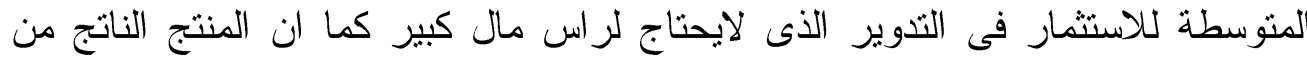

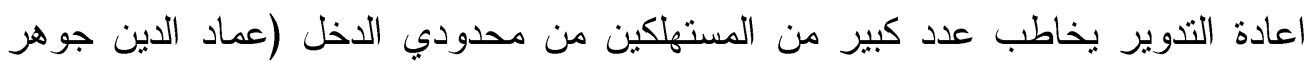

$$
(r \cdot) r_{-}
$$

Fashion الموضة

يعرف قاموس ويستر الموضة على انها القبول او الموافقة على استعمال شئ ما فى وقت معين من بعض الفئات التى تملك القدرة على ان تكون على طر از فى مجال الموضة (غادة

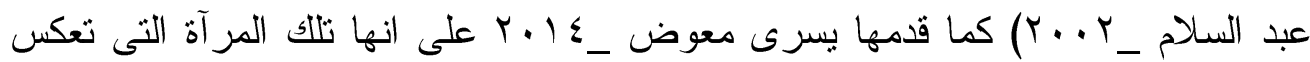
التطور ات و الاحداث الجارية حول العالم عامة وداخل المدن وقدمتها تحية كامل _r... على انها الجديد و المبتكر و المستحدث و المستلهم مع كل موسم من فصول السنةلالربعة

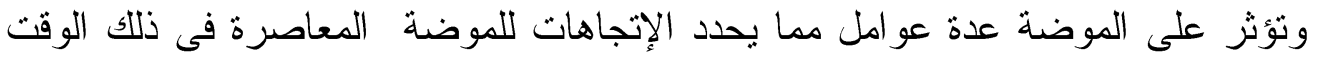


ومنها العوامل الإقتصادية _العوامل الاجتماعية _العوامل السياسية - التقدم العلمى -

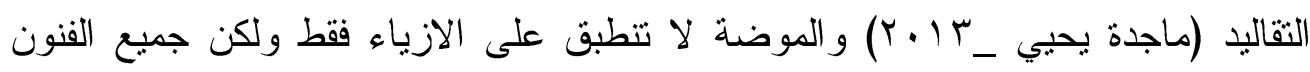

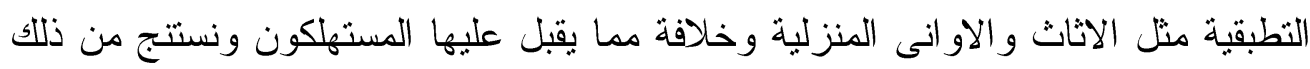
العلاقات الوثيقة النى نربط الموضة بالحياة اليومية من التغير ات ف فالتغير سنة كونية.

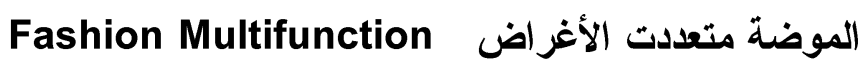

الموضة متعددة الاغر اض فى الملابس يقصد بها ثلك الملابس ذات الإنتخدامات المتعددة

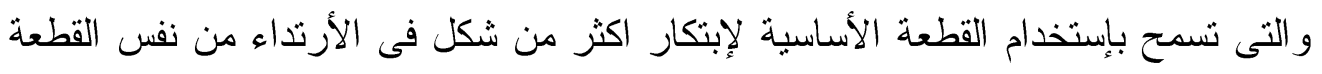

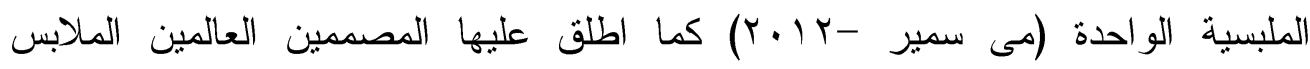
المتحولة او المتغيرة وقدم المصمح العالمى (توم براوت) تصميمات مميزة فى مجموعنة

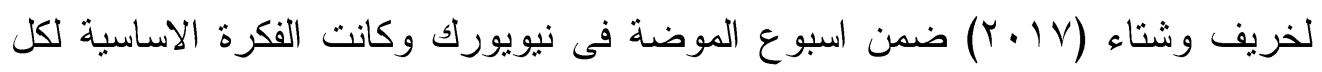

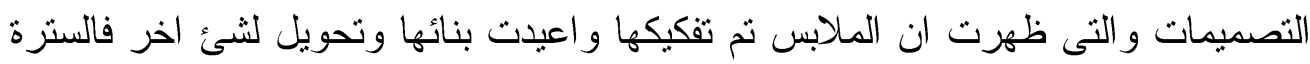
تجدها تحولت إلى تنورة ،وجزء من المعطف تحول فستان (عماد الدين جوهر _2017) وقد تم عرض الملابس المتحولة كما يطلق عليها فى بعض المون اقدع التجارية الأكترونية منها موقع Travel Fashion Girl على انها ملابس مناسبة للسفر و الرحلات (www.travelfashiongirl.com)

ومن الواضح أن الموضة المتعددة الإستخدام فى الملابس لها عدة إتجاهات الأتجاة الأول

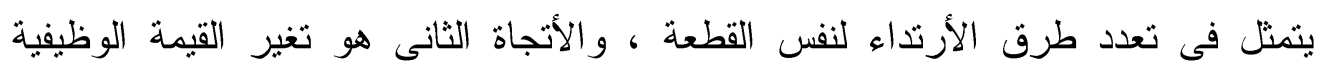

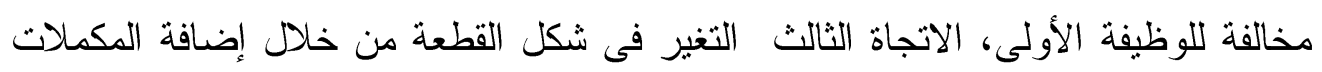

$$
\text { (الجانب سمير _ التطبيقى: • (r) }
$$

تم إعادة تدوير 1 بنطلونات حريمى مستعملة من خامات مختلفة (جينز ،فسكوز ،ليكر ا) ونم

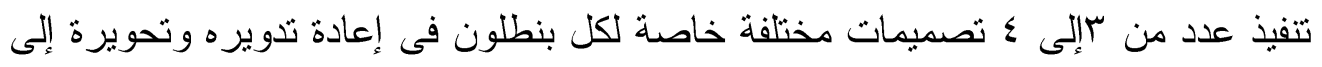

ملبس منعدد الإستخدامات ، تم تحويل كل بنطلون إلى (جونلة - شنطة - فستان -جلية )

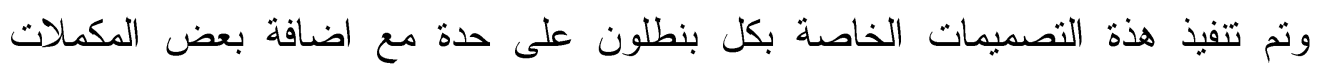
المتصلة لرفع القيمة الجمالية للتصميمات.

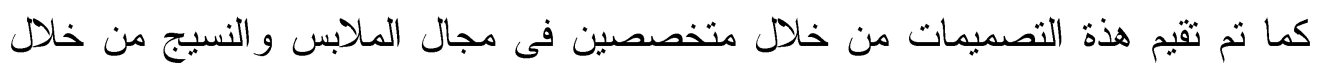
إستمارة إستنيان تحتوى على ع محاور رئيسية هى (اسس التصميم -عناصر التصميم الجانب الأبتكارى -تحقق الجانب الوظيفى ) ونم تحليل البيانات إحصائيا لاستخلاص النتائج. 
الموديل الأول

جدول (1) يوضح الوصف التفصيلي للموديل الأول قبل وبعد اعادة التدوير

\begin{tabular}{|c|c|c|}
\hline & \multicolumn{2}{|c|}{ الموديل قبل إعادة التدوير } \\
\hline & 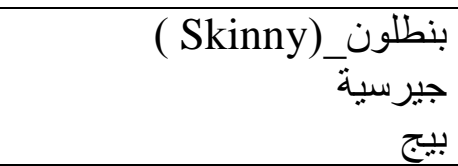 & الخامة اللونيل \\
\hline & \multicolumn{2}{|r|}{ الموديل بعد التدوير } \\
\hline & 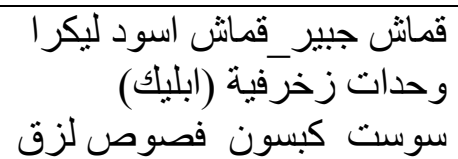 & الخمامات المستخدمة المكاف \\
\hline & (أ)(الجونلَة_(ب) (ب) الكاب الحريمى & الإغر اض الوظيفية \\
\hline
\end{tabular}

التصميمات المنفذة من الموديل الأول بعد اعادة التدوير بالإتجاهات المتعددة الأغراض

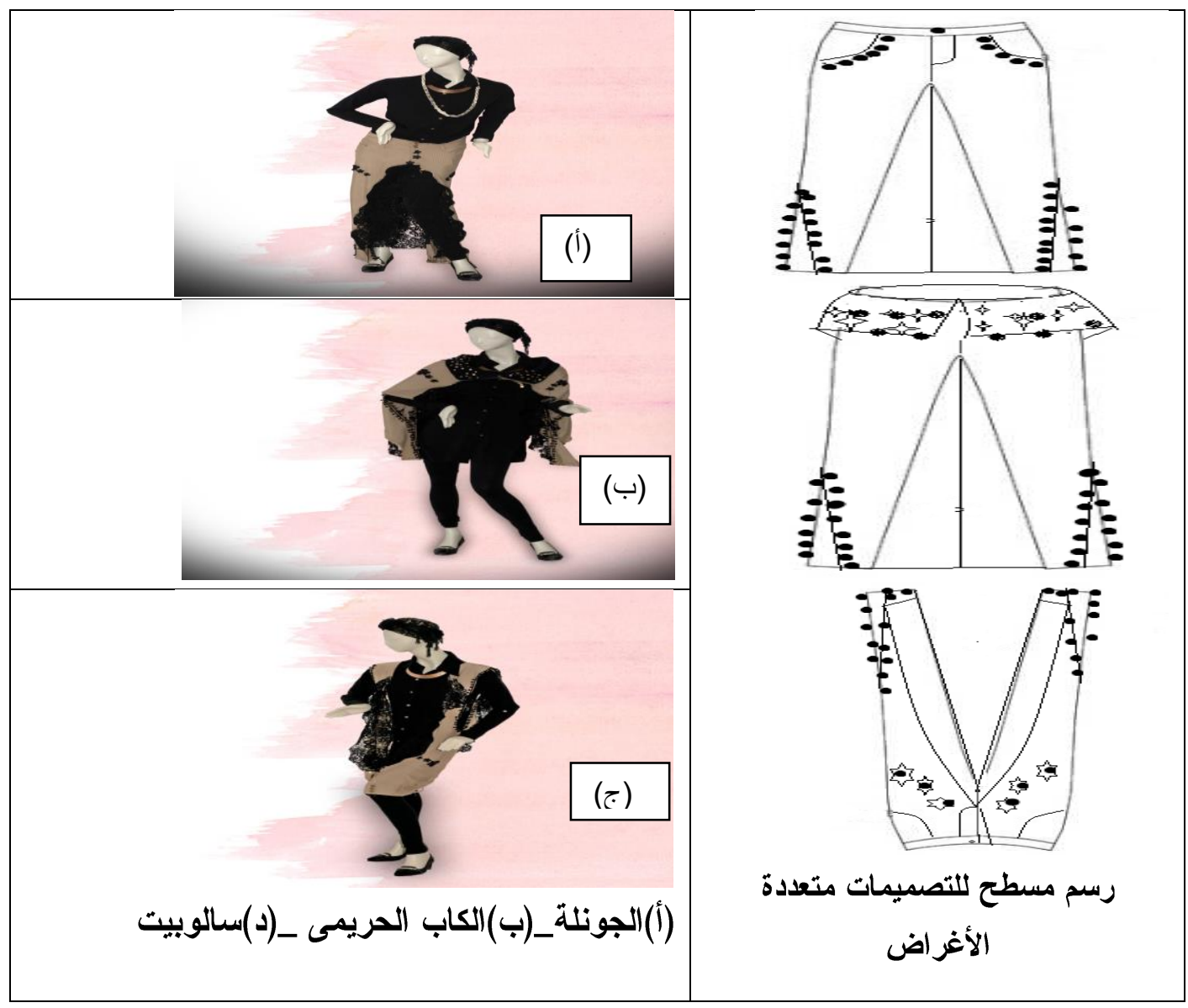




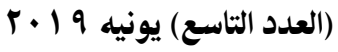

المجلة العلمية لعلوم التربية النوعية

المودبيل الثانحى

جدول (r) يوضح الوصف التفصيلي للموديل الثاني قبل وبعد اعادة التدوير

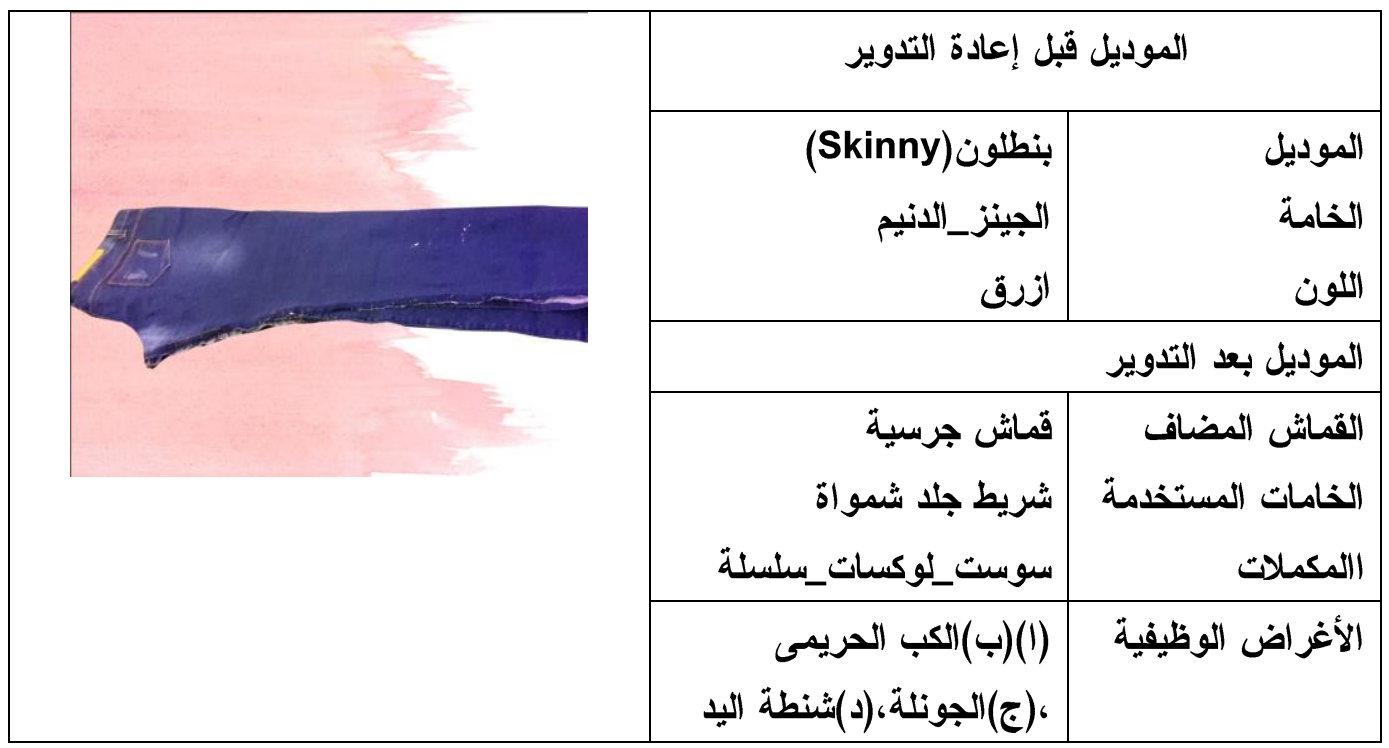

التصميمات المنفذة من الموديل الثاني بعد اعادة لتدوير بالإتجاهات المتعددة الأغراض

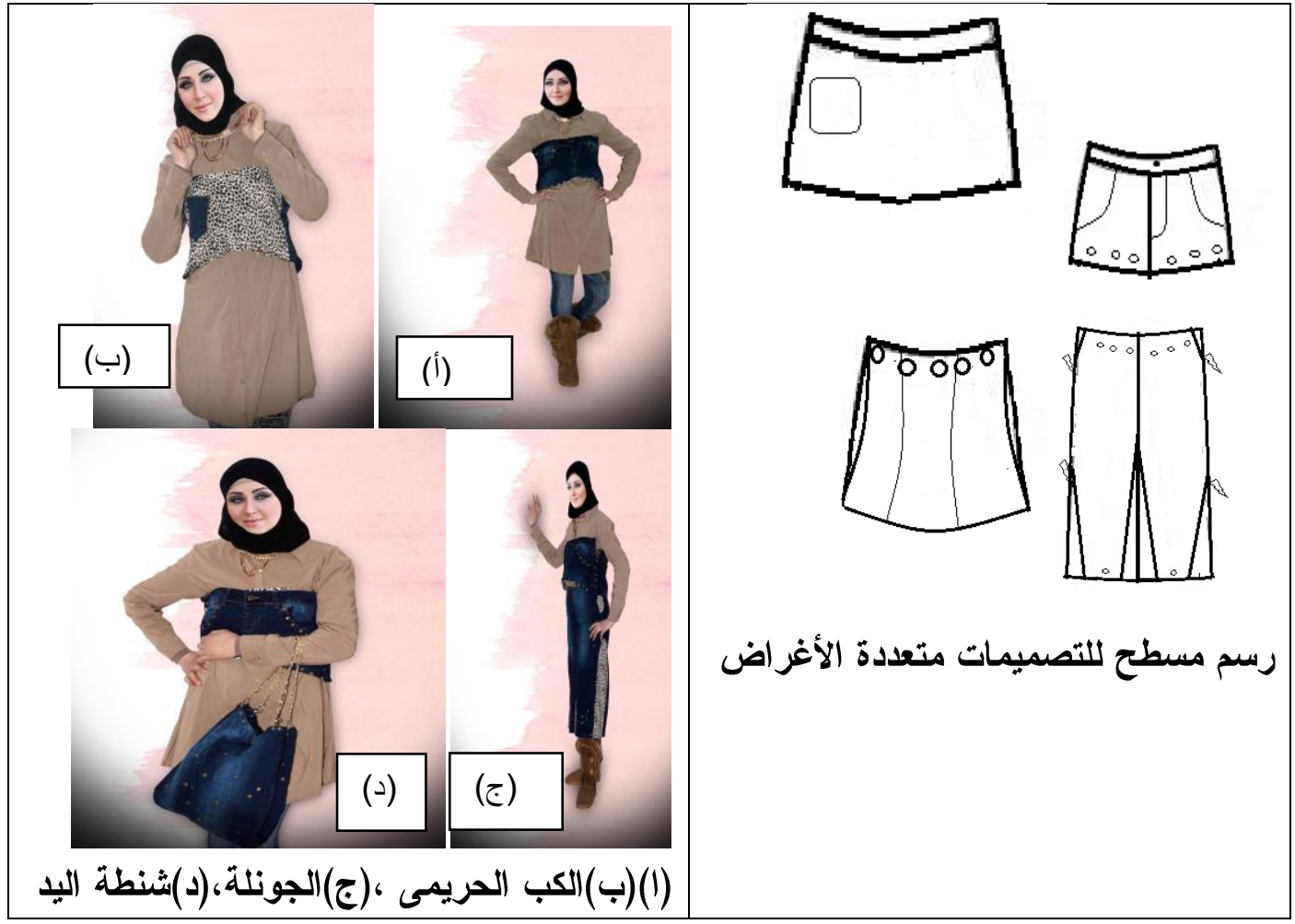




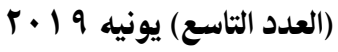

المجلة العلمية لعلوم التربية النوعية

الموديل الثالث

جدول (r) يوضح الوصف التفصيلي للموديل الثالث قبل وبعد اعادة التدوير

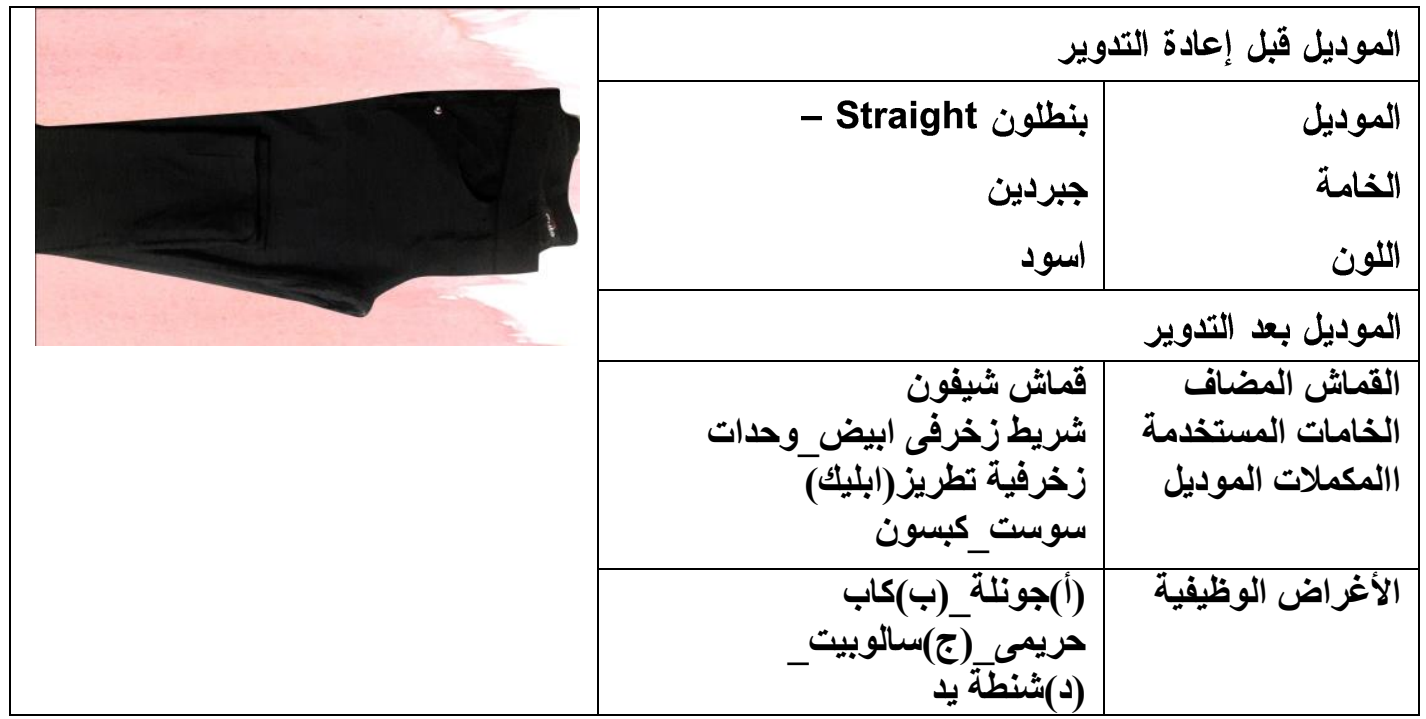

التصميمات المنفذة من الموديل الثالث بعد اعادة لتدوير بالإتجاهات المتعددة الأغراض لاض

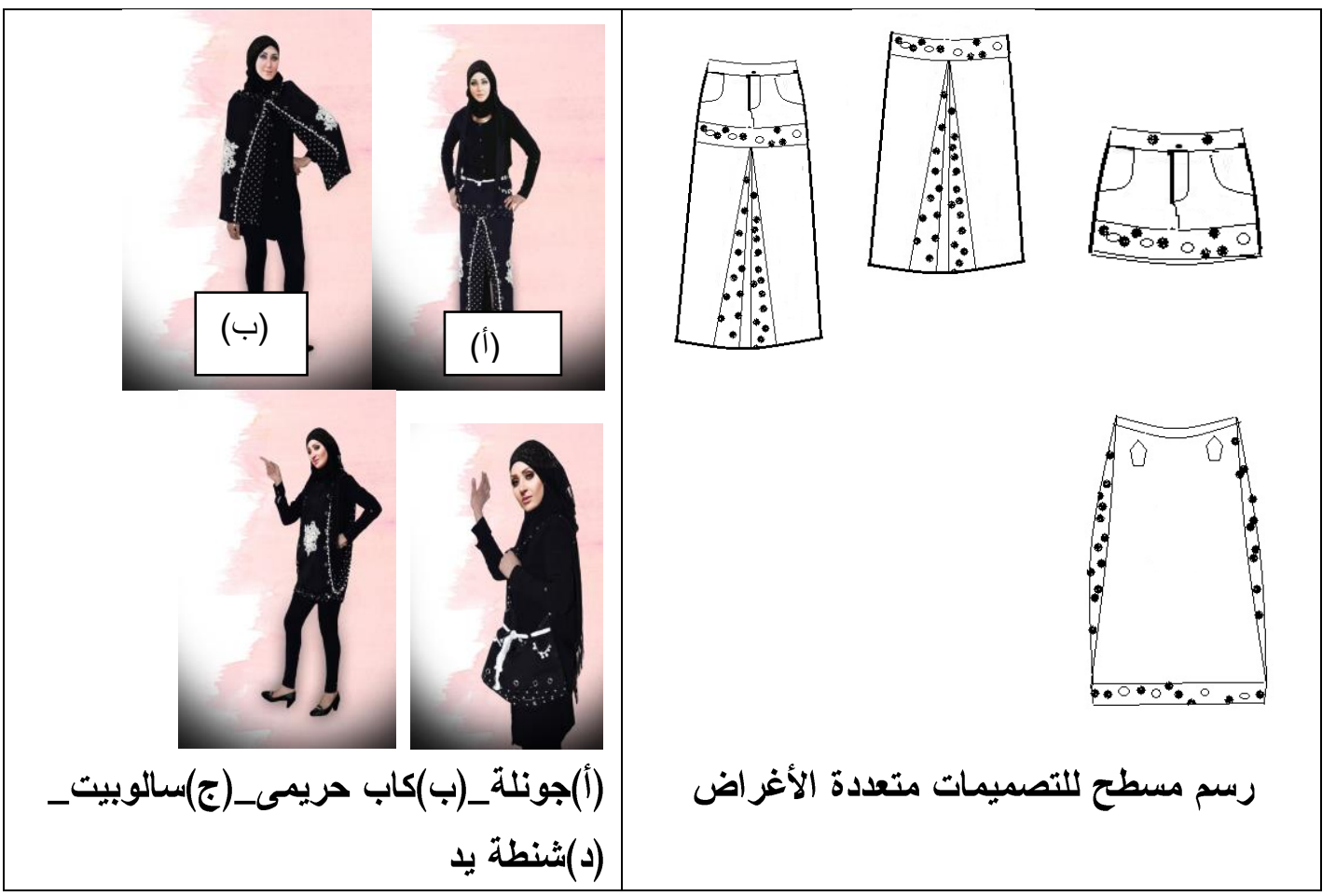


المودبيل الرابع

جدول (ع) يوضح الوصف التفصيلي للموديل الرابع قبل وبعد اعادة التدوير

\begin{tabular}{|c|c|c|}
\hline & & الموديل قبل إعادة التً \\
\hline 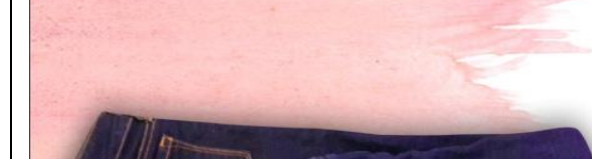 & 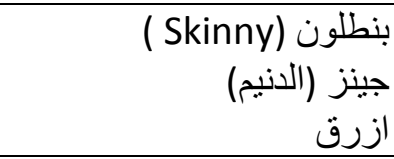 & الخامة اللونيل \\
\hline & & الموديل بعد التدوير \\
\hline & 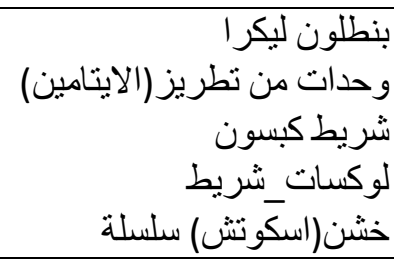 & الخمامات المستخدمة المضاف \\
\hline & بنطلون_جلية_شنطة كروس & الأغر اض الوظيفية \\
\hline
\end{tabular}

التصميمات المنفذة من الموديل الرابع بعد اعادة لتدوير بالإتجاهات المتعددة الأغراض

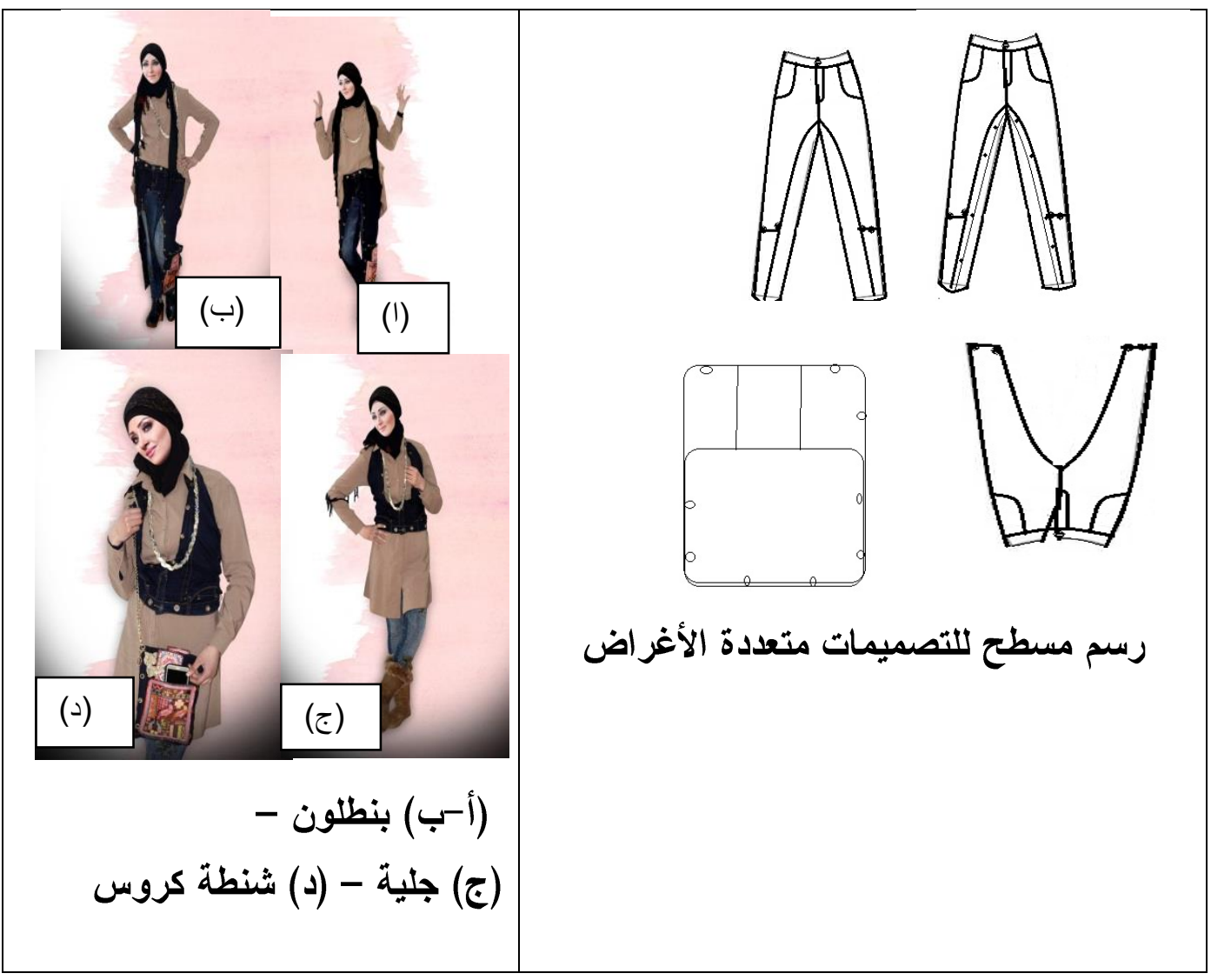




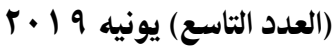

المجلة العلمية لعلوم التربية النوعية

الموديل الخامس

جدول (0) يوضح الوصف التفصيلي للموديل الخامس قبل وبعد اعادة التدوير

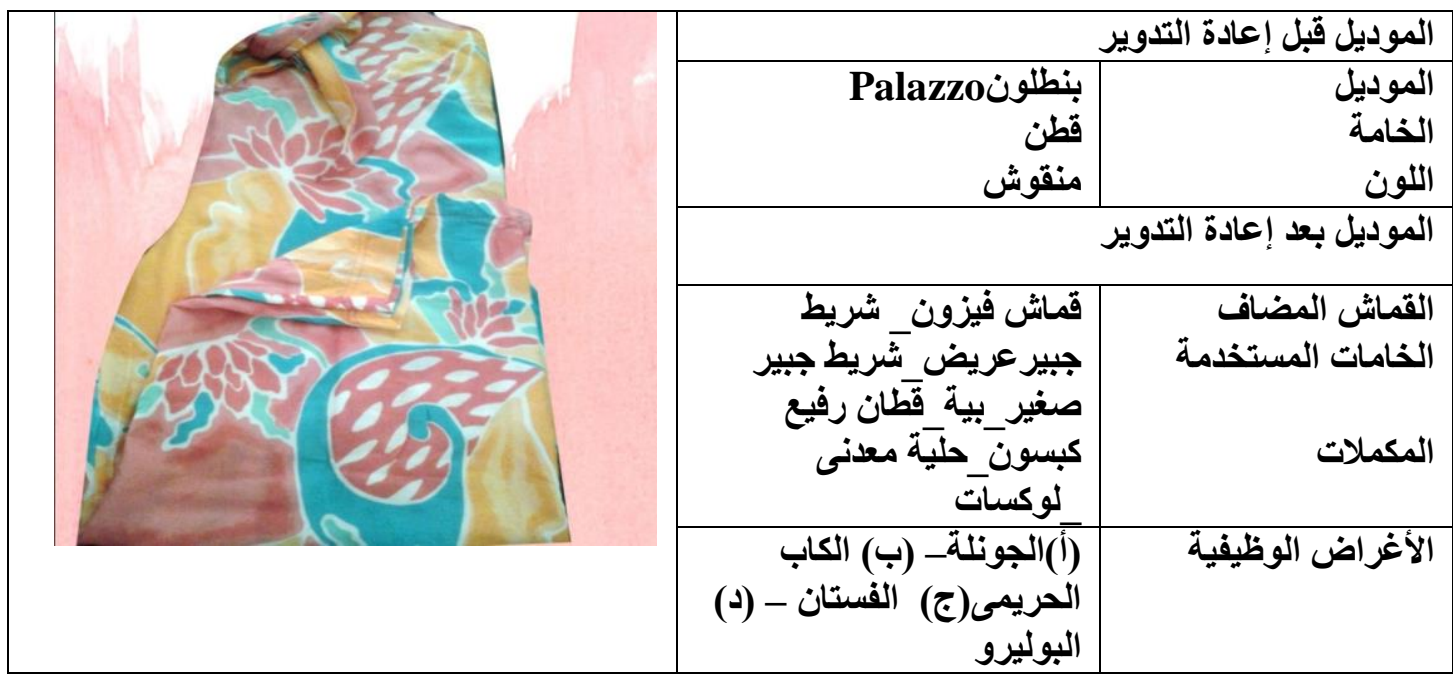

التصميمات المنفذة للموديل الخامس بعد اعادة التدوير بالإتجاهات المتعددة الأغراض

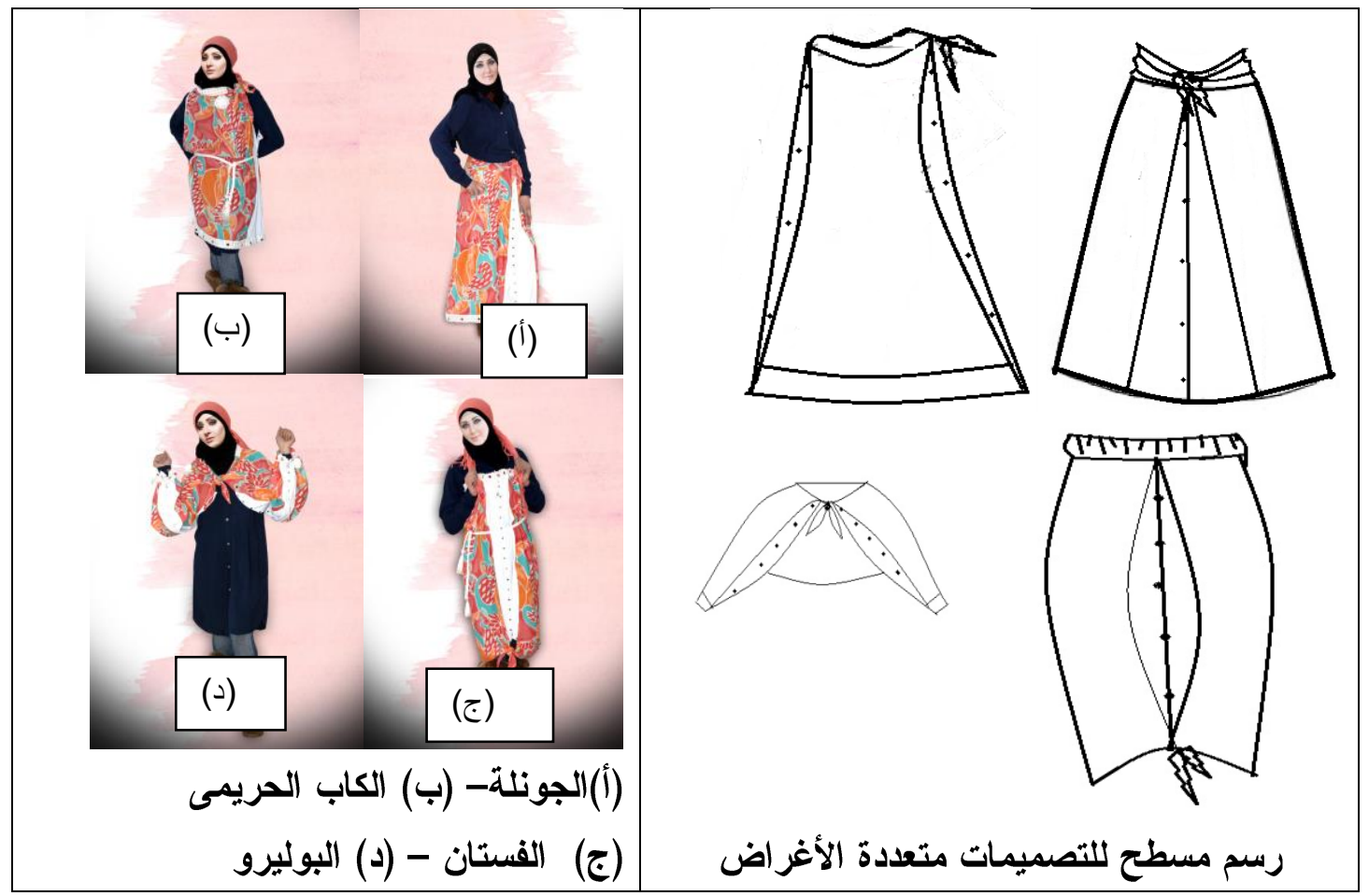



جدول (†) يوضح الوصف التفصيلي للموديل السادس قبل وبعد اعادة التدوير

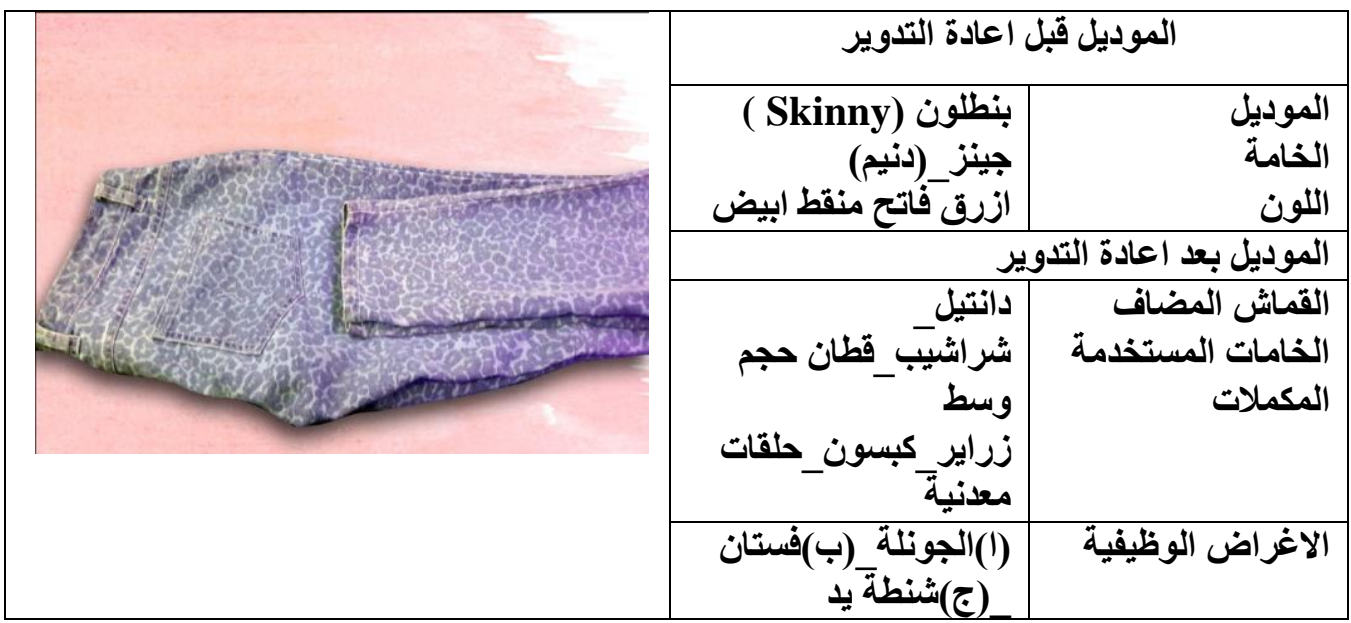

التصميمات المنفذة للموديل السادس بعد اعادة التدوير بالإتجاهات المتعددة الأغراض

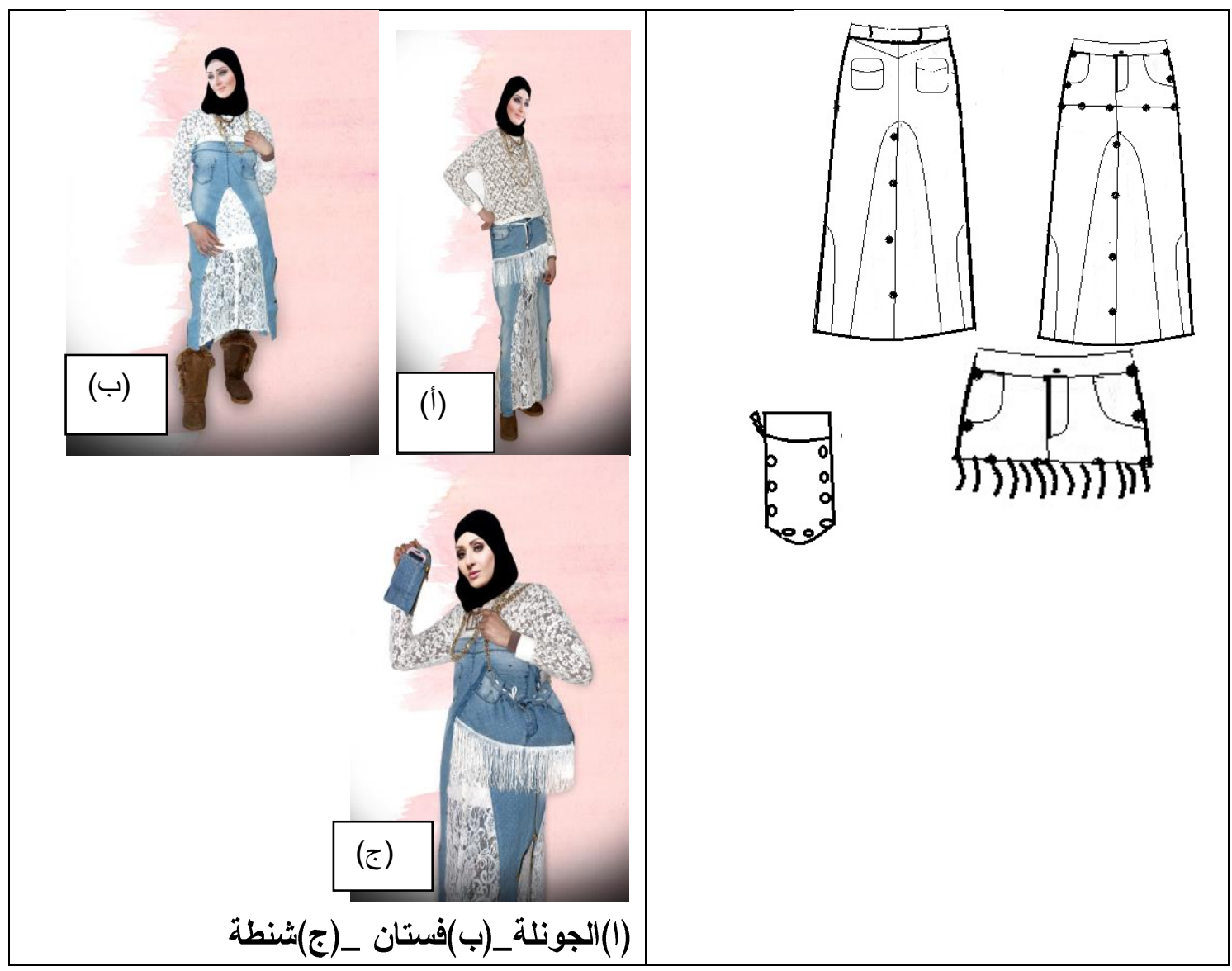


لتحقيق محاور الاستبيان نم الإطلاع على الدراسات السابقة والبحوث و الدراسات المتعلقة بالاتجاهات متعددة الاغر اض بالموضة ، تدوير الملابس ومن هنا استطاعت الباحثة تحقيق

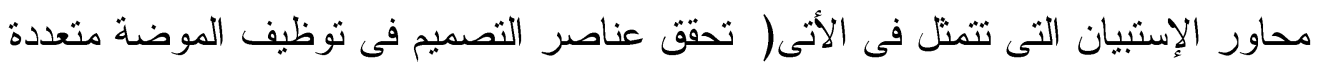

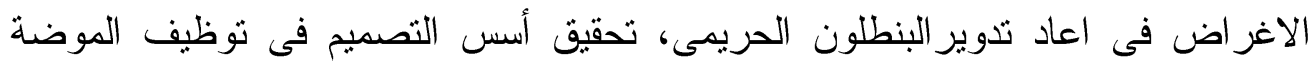
متعددة الاغراض فى البنطلون الحريمى، تحقيق الجانب الابتكارى فى توظيف الموضة لهئ

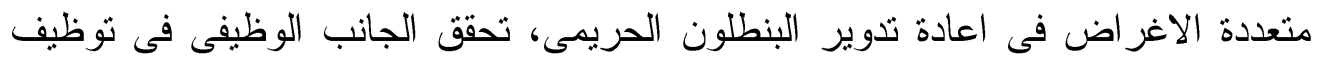

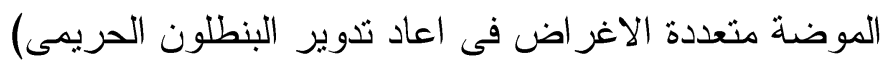
وقد تم عرض الاستبيان فى صورثه الاولى على ( • () من المحكمين لتحديد نسب الاتفاق بين المحكمين جـــول ( V ) نسب الإتفاق بين المحكمين على صلاحية كل عبارة فى الإستبيان

\begin{tabular}{|c|c|c|c|c|c|}
\hline النسبة (\%) & عدد المتفقين & رقم العبارة & النسبة (\%) & عدد المتفقين & رقم العبارة \\
\hline$\% \wedge$. & $\overline{\Lambda \Lambda}$ & 1. & $\%$ & 1. & 1 \\
\hline$\%$ & 1. & 11 & $\% 9$. & 9 & $r$ \\
\hline$\% 9$. & 9 & Ir & $\% 1 \ldots$ & 1. & $r$ \\
\hline$\% 1 \ldots$ & 1. & 14 & $\% \wedge$. & $\Lambda$ & $\varepsilon$ \\
\hline$\% 1 \ldots$ & 1. & $1 \varepsilon$ & $\% 9$. & 9 & 0 \\
\hline$\% \wedge$. & $\Lambda$ & 10 & $\% 1 \ldots$ & 1. & 7 \\
\hline$\% 9$. & 9 & 17 & $\%$ \% & $\varepsilon$ & $\mathrm{V}$ \\
\hline$\%$ & 7 & IV & $\%$ \%. & $\Lambda$ & $\Lambda$ \\
\hline$\% 1 \ldots$ & 1. & 11 & $\% 1 \ldots$ & 1. & 9 \\
\hline
\end{tabular}

وفى ضوء إتفاق المتخصصين استبقت الدارسة على البنود التى حصلت على نسبة إتفاق

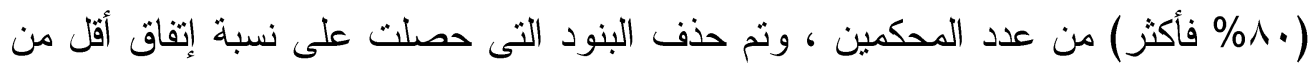

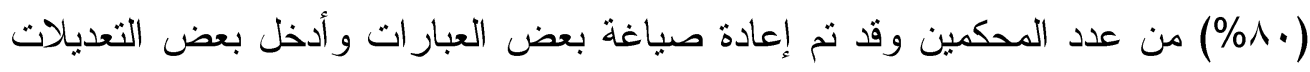
عليها بناءاً علي ملاحظات المحكمين.

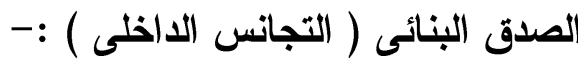
و الصدق البنائي يقاس بالتجانس الداخلي Internal Consistency لاختبار مدى تماسك مفرداته. وهى تعد كافية للتأكد من صدق الاستبيانات الجديدة. 


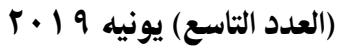

جدول ( ^ ) معاملات ارتباط التوافق بين درجات كل عبارة و الدرجة الكلية للإستبيان

\begin{tabular}{|c|c|c|c|c|c|}
\hline الدلالة & معامل الارتباط & العبارة & الالاكة & معامل الارتباط & العبارة \\
\hline$\ldots$ & $* *, V 17$ & 9 & $\cdots$ & $* *, \wedge 07$ & 1 \\
\hline$\cdots$ & **, , & 1. & $\cdots$ & $* *, V \cdot V$ & $r$ \\
\hline$\because \cdots$ & $* *, V q V$ & 11 & $\therefore \cdots$ & $* *, \wedge \leqslant \mu$ & $\mu$ \\
\hline$\cdots$ & $* *, \quad \wedge \leqslant r$ & Ir & $\cdots$ & $* *, 70 \leqslant$ & $\varepsilon$ \\
\hline$\because \cdots$ & $* *, 707$ & 14 & $\because \cdots$ & $* *, \vee \vee q$ & 0 \\
\hline$\because \cdots$ & $* * ., 79 \mathrm{~V}$ & 15 & $\because \cdots$ & $* *, 7 \vee 7$ & 9 \\
\hline$\cdots$ & $* *$, V91 & 10 & $\cdots$ & $* *$, 人 & V \\
\hline$\because \ldots$ & $* *, V \leq$. & 17 & $\because \cdots$ & $* *, \vee \vee \vee$ & $\Lambda$ \\
\hline
\end{tabular}

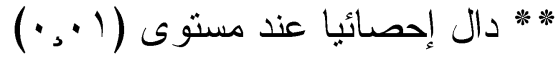

ويلاحظ من الجدول أن جميع قيم معاملات الارتباط تشير إلى دلالتها الإحصائية عند

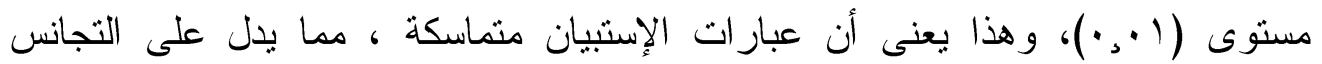

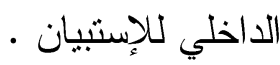
جدول ( 9 ) معامل الإرتباط بين درجة كل عبارة والارجة الكلية للمحور الذى تنتمى إليه العبارة

\begin{tabular}{|c|c|c|c|c|c|}
\hline الدلالة & معامل الارتباط & العبارة & |الالاكة & معامل الارتباط & العبارة \\
\hline \multicolumn{3}{|c|}{ المحور الثالث } & \multicolumn{3}{|c|}{ المحور الأول } \\
\hline$\because \cdots$ & $* *, \mathrm{~V} 0$. & 9 & $\because$ & $*, V \leq$. & 1 \\
\hline$\because \cdots$ & $* *, 77 V$ & 1. & $\ldots$ & $* *, \wedge 17$ & $r$ \\
\hline$\because$ & $* *, \Lambda \leq Y$ & 11 & - & $* *, \wedge 9$. & $r$ \\
\hline$\because$ & $* *, 7 \wedge \mathrm{V}$ & Ir & . & $* *, 117$ & $\varepsilon$ \\
\hline \multicolumn{3}{|c|}{ المحور الرابع } & \multicolumn{3}{|c|}{ المحور الثانى } \\
\hline$\because \cdots$ & $* *, 1899$ & 14 & $\cdot$ & $* *, 77 V$ & 0 \\
\hline$\because \cdots$ & $* *, \wedge 9 \varepsilon$ & $1 \leq$ & 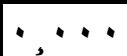 & $*, 0 \% q$ & 7 \\
\hline$\because \cdots$ & $* *, V \leq 0$ & 10 & $\because \cdots$ & $* * ., 79 V$ & $\mathrm{~V}$ \\
\hline$\because \cdots$ & $* .799$ & 17 & $\because \cdots$ & $* *, V \leq q$ & $\Lambda$ \\
\hline
\end{tabular}

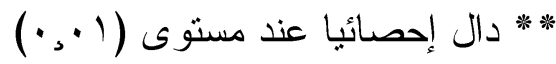


ويلاحظ من الجدول أن جميع معاملات الارتباط دالة إحصائيا عند مستوى( ( •. •) من

الثقة، وهذا يشير إلى أن عبار ات الإستبيان منماسكة، وتتنمي كل عبارة إلى المحور الذي الذي يتضمنها.

ثانياً : ثبات الاستبيان:للتأكد من ثبات الاستبيان نم حساب معامل الاتساق الداخلي بواسطة معادلة ألفا كرونباخ Alpha جدول ( • 1 ) معامل الثبات ألفا كرونباخ لمحاور استبيان المحكمين

\begin{tabular}{|c|c|}
\hline قيمة معامل الثبات & المحـــــاور \\
\hline$\because \vee \vee 9 \wedge$ & الاغر اض فيى اعاد تدوير الميلابس فتيف المستعملة الموضة متعددة \\
\hline$\because$ VYO & الاغقيق أسس في التصاد تدوير فى الملابس المستعملة الموضة متعددة \\
\hline$\cdot, \wedge \wedge r$ & 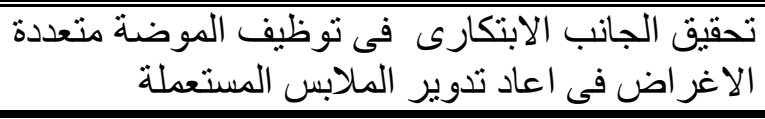 \\
\hline$\cdot, \Lambda \mid r$ & 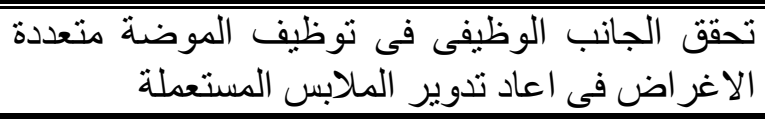 \\
\hline$\cdot, \Lambda \cdot \varepsilon$ & ثبات الأداة الكلي \\
\hline
\end{tabular}

وفي ضوء نتائج معاملات الثبات لمحاور الاسنبيان الأربعة الرئبسة الموضحة بالجدول السابق، لم يتم حذف أبي محور من المحاور، حيث كانت معاملات الثبات مرتفعة في كل

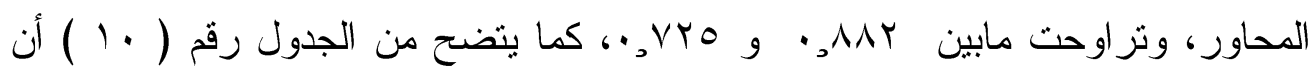

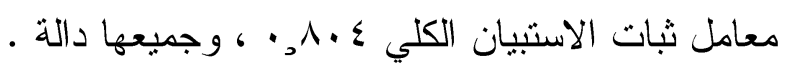
صياغة الاستبيان فى صورته النهائية :

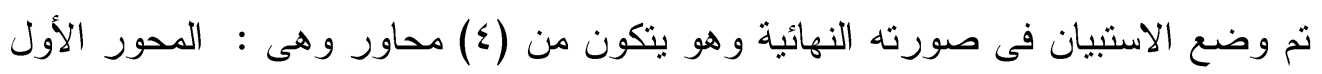

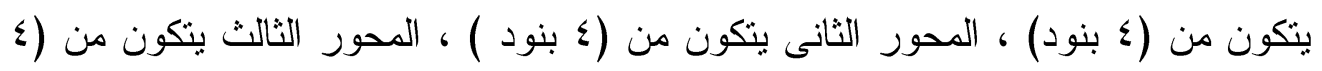
بنود) ، المحور الر ابع يتكون من (ع بنود). 
(العدد التاسع) يونيه 9 | P T

\section{المعاملات الإحصائية التى استخدمت في تحليل البيانات:} تم تحليل البيانات وإجر اء المعاملات الإحصائية باستخدام برنامج spss لاستخر اج النتائج وفيما يلي بعض الأساليب الإحصائية المستخدمة :

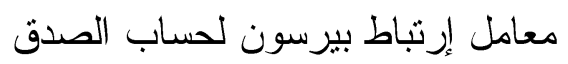

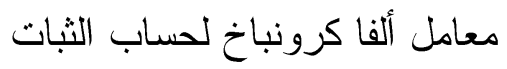
المتوسط المرجح و المتوسط المئوى المرجح (معامل الجودة)

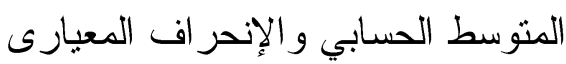
تحليل التباين (ANOVA)

النتائج المتعلقة بالفرض الأول :عدد المحكمين( ن )= "يوجد فروق ذات دلالة إحصائية بين متوسطات أراء المحكمين على التصميمات المقترحة فى تحقق عناصر التصميم فى توظيف الموضة متعددة الاغر اض فى اعاد تدوير الملابس المستعملة" للتحقق من صحة هذا الفرض نم حساب المتوسط المرجح والمنوسط المئوى المرجح و الإنحراف المعيارى لأراء المتخصصين حول التصميمات المقترح بالنسبة لاعادة تدوير البنطلون. 
جذول ( 11 ) المتوسط المرجح والمتوسط المئوى المرجح والإحر اف المعيارى لأراء المتخصصين حول التصميمات المقترحة من اعادة تدوير البنطلون فيتحقيق عناصر التصميم.

\begin{tabular}{|c|c|c|c|c|c|c|c|c|c|c|}
\hline \multirow[b]{2}{*}{ التصميم } & \multirow[b]{2}{*}{ 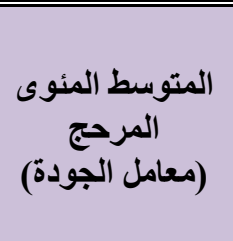 } & \multirow[b]{2}{*}{ 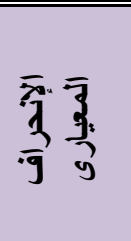 } & \multirow{2}{*}{ 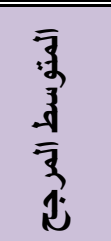 } & \multirow{2}{*}{ 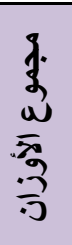 } & \multicolumn{3}{|c|}{ مستويات المؤشر ات } & \multirow[b]{2}{*}{ 司 } & & \multirow[b]{2}{*}{ الاوحور } \\
\hline & & & & & $\begin{array}{l}.9 . \\
.3 \\
3\end{array}$ & $\frac{\sqrt[3]{3}}{3} \cdot \frac{1}{3}$ & 争 & & & \\
\hline مناسب & $\% 9 \wedge, r \leqslant$ & $\cdot, \cdot r$ & r.q६ & 09 & . & 1 & 11 & 1 & & \\
\hline مناسب & $\% 99, \leqslant 9$ & $\cdot, \cdot \varepsilon$ & $r, \wedge q$ & 00 & . & r & iv & $r$ & & \\
\hline مناسب & $\%$ ^৭. 々 V & $\cdot, Y Y$ & $r, 7 \wedge$ & 01 & . & 7 & ir & $r$ & & \\
\hline مناسب & $\% q 1, r r$ & $\cdot, r_{1}$ & $r, V r$ & or & . & 0 & $1 \varepsilon$ & $\varepsilon$ & & \\
\hline مناسب & $\% q \varepsilon, \vee r$ & $\cdot, 1 \varepsilon$ & $r, \wedge \varepsilon$ & $0 \leqslant$ & . & $r$ & 17 & 0 & 岳 & \\
\hline مناسب & $\% 9 \wedge, r \leqslant$ & $\cdot, \cdot r$ & Y. $9 \varepsilon$ & 09 & . & 1 & 11 & 7 & & \\
\hline مناسب & $\% 97, \leqslant 9$ & $\cdot, \cdot \xi$ & $r, \wedge q$ & 00 & . & $r$ & IV & $v$ & & \\
\hline مناسب & $\% q \varepsilon, \vee r$ & $\cdot, 1 \leq$ & $r, \wedge \varepsilon$ & $0 \leqslant$ & . & $r$ & 17 & $\wedge$ & & \\
\hline مناسب & $\% 9 \varepsilon, V \Gamma$ & $\cdot, 1 \leqslant$ & $r, \wedge \varepsilon$ & $0 \leqslant$ & . & $r$ & 17 & 9 & $\underline{E}$ & \\
\hline مناسب & $\% 94, \leqslant 9$ & $\cdot, \cdot \varepsilon$ & $r, \wedge q$ & $\Delta$ & - & $r$ & iv & 1. & $\underset{\xi}{E}$ & 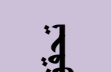 \\
\hline مناسب & $\% 9 \wedge$, , $\varepsilon$ & $\cdot, \cdot r$ & T.q\& & 04 & . & 1 & 11 & 11 & & \\
\hline مناسب & $\%^{\wedge \varepsilon, \Gamma)}$ & $\cdot, 44$ & $r, \Delta r$ & $\leqslant \Lambda$ & . & 9 & 1. & ir & $\pi$ & 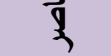 \\
\hline مناسب & $\% 9 \wedge, r \varepsilon$ & $\cdot, \cdot r$ & Y.9ะ & 07 & . & 1 & 11 & 14 & 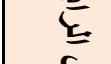 & 司 \\
\hline مناسب & $\% 99, \leqslant 9$ & $\cdot, \cdot \varepsilon$ & $r, \wedge q$ & 00 & . & $r$ & IV & $1 \leq$ & 6 & 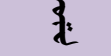 \\
\hline مناسب & $\% q \varepsilon, \vee r$ & $\cdot, 1 \leq$ & $r, \wedge \varepsilon$ & $0 \leq$ & . & $r$ & 17 & 10 & & \\
\hline مناسب & $\% 94.91$ & $\cdot, I V$ & r.v & or & . & $\varepsilon$ & 10 & 17 & $\varepsilon$ & \\
\hline مناسب & $\% q \varepsilon, \vee r$ & $\cdot, 1 \leq$ & $r, \wedge \varepsilon$ & $0 \leqslant$ & - & $r$ & 17 & iv & $\underline{\underline{F}}$ & \\
\hline مناسب & $\% q 1, r r$ & $\cdot, r$ & $r, V r$ & or & . & 0 & $1 \varepsilon$ & 11 & $\frac{E}{4}$ & \\
\hline مناسب & $\%$ \% Y.\&O &. . & r. $\leqslant V$ & $\leqslant v$ & - & 1. & 9 & 19 & & \\
\hline مناسب & $\% \wedge \vee$ \% & . Y & T.T & 0. & . & v & ir & $r$. & & \\
\hline مناسب & $\% 1 \ldots$ & . & $r$ & ov & . & . & 19 & Y & $=\sum_{E}^{E}$ & \\
\hline مناسب & $\% 94, \leqslant 9$ & $\cdot, \cdot \varepsilon$ & $r, \wedge q$ & 0 & . & r & iv & rr & & \\
\hline
\end{tabular}




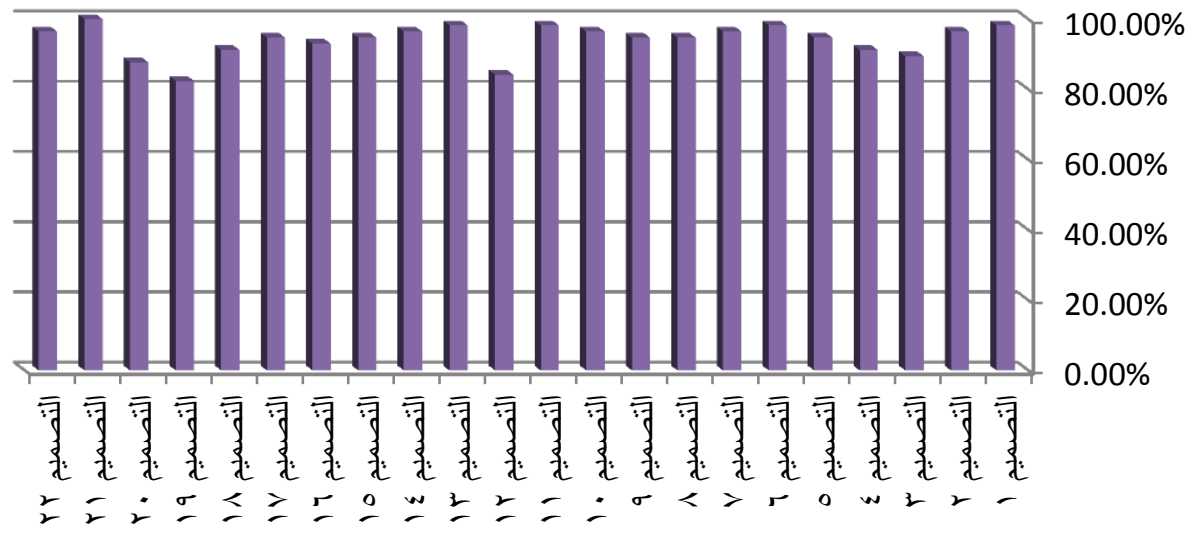

شكل ( 1 ) ترتيب التصميمات المقترحه من اعادة تدوير البنطلون وفق معاملات الجودة لأراء المتخصصين فى تحقق عناصر التصميم

نستخلص من الجدول ( 11 ) و الثنكل ( 1 ( ) :

إثقاق أراء السادة المتخصصين حول التصميمات المقترحة في تحقق عناصر التصميم

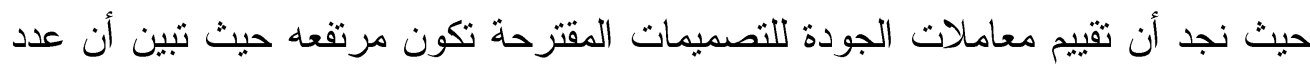

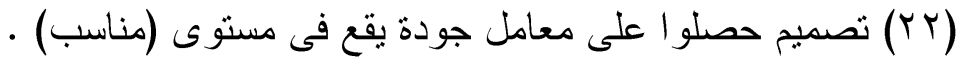

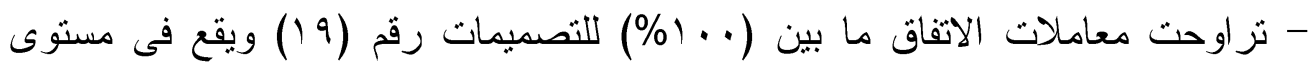

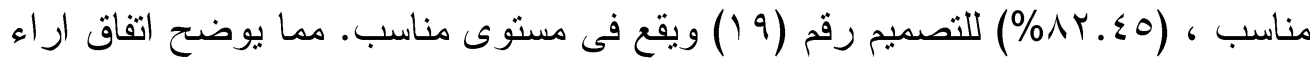

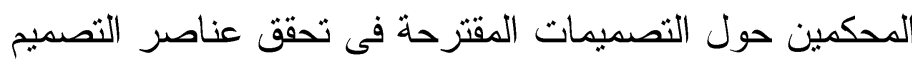

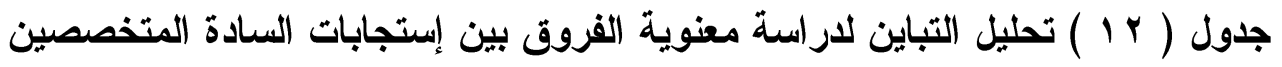

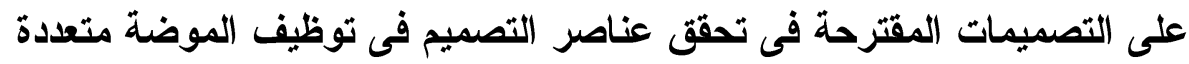

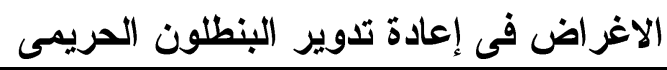

\begin{tabular}{|c|c|c|c|c|c|c|c|}
\hline مستولة & الدلالة & $\mathbf{F}$ & المربعات & المربعوتات & الرجرية & مصدر التباين & المحور الاول \\
\hline \multirow{3}{*}{ 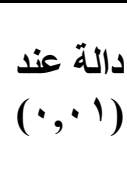 } & \multirow{3}{*}{$\cdot, \cdots$} & \multirow{3}{*}{$r, \leqslant Y V$} & $\cdot, r \leq \varepsilon$ & V,Yrs & $Y$ & بين التصميمات & \multirow{3}{*}{ تحقت عناصر } \\
\hline & & & $\cdot, 1 \leqslant r$ & 07,511 & r99 & داخل التصميمات & \\
\hline & & & - & $T r, \leqslant \leq 0$ & $\varepsilon 1 V$ & الإجمالى & \\
\hline
\end{tabular}

نستلخص من الجدول ( I r ) : وجود فروق ذات دلالة إحصائيه عند مستوى دلالة (1 +., بين إستجابات السادة المتخصصين على التصميميات المقترحة فى تحقق عناصر

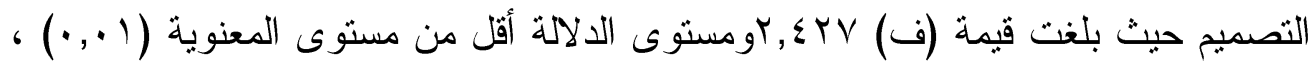
مما يدل على وجود فروق بين التصميمات فى هذا المحور ـ مما يؤكد تحقق الفرض الاول 
(r) النتائج المتعلقة بالفرض الثانىى

"يوجد فروق ذات دلالة إحصائية بين متوسطات أراء المحكمين على التصميمات المقترحة تحقيق أسس التصميم فى توظيف الموضة متعددة الاغر اض فى إعادة تدوير البنطلون الحريمى وللتحقق من صحة هذا الفرض تم حساب المتوسط المرجح و المتوسط المئوى المرجح والإنحراف المعيارى لأر اء المتخصصين حول التصميمات المقترحة بالنسبة

$$
\text { لاعادة تدوير البنطلون. }
$$

جدول (r ا المنوسط المرجح و المتوسط المئوى المرجح والإنحر اف المعيارى لأراء

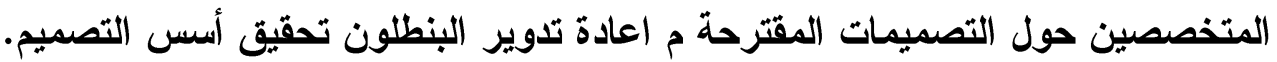

\begin{tabular}{|c|c|c|c|c|c|c|c|c|c|c|}
\hline \multirow[b]{2}{*}{ مستوى التصميم } & \multirow{2}{*}{$\begin{array}{c}\text { المئوى المرسط } \\
\text { المعامل } \\
\text { الجودة) }\end{array}$} & \multirow[b]{2}{*}{$\frac{7}{3} \frac{9}{3}$} & \multirow[b]{2}{*}{ 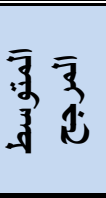 } & \multirow[b]{2}{*}{$\begin{array}{l}3 . \bar{x} \\
\vdots .3 \\
\omega .5\end{array}$} & \multicolumn{3}{|c|}{ مستويات المؤشرات } & \multirow[b]{2}{*}{ 牙 } & & \multirow[b]{2}{*}{ الاول } \\
\hline & & & & & $q_{1}=\frac{7}{3}$ & & -3. & & & \\
\hline مناسب & $\%$ & $\cdot, r_{0}$ & $r, \leqslant Y$ & $\{7$ & . & 11 & $\bar{\Lambda}$ & 1 & & \\
\hline مناسب & $\% q \leq, \vee r$ & $\cdot, 1 \leq$ & $r, \wedge \varepsilon$ & $0 \leqslant$ & - & $r$ & 17 & r & & \\
\hline مناسب & $\% 97, \leqslant 9$ & $\cdot, \cdot \varepsilon$ & $r, \wedge q$ & 00 & - & r & iv & $r$ & & \\
\hline مناسب & $\% q \wedge, Y \leq$ & $\cdot, \cdot r$ & Y. $9 \varepsilon$ & 07 & - & 1 & 11 & $\varepsilon$ & & \\
\hline مناسب & $\% 91, r r$ & $\cdot, r$ & r,vr & or & - & 0 & $1 \varepsilon$ & 0 & & \\
\hline مناسب & $\% 97, \leqslant 9$ & $\cdot, \cdot \varepsilon$ & $r, \wedge q$ & 00 & - & r & iv & 7 & & \\
\hline مناسب & $\% 97,89$ & $\cdot, \cdot \varepsilon$ & $r, \wedge q$ & 00 & - & $r$ & iv & $v$ & & \\
\hline مناسب & $\% \wedge 9 .\{\vee$ & $\cdot, r Y$ & $r, 7 \wedge$ & 01 & $\dot{-}$ & 7 & ir & $\Lambda$ & & \\
\hline مناسب & $\% q \leq, \vee r$ & $\cdot, 1 \leq$ & $r, \wedge \varepsilon$ & $0 \leqslant$ & - & $r$ & 17 & 9 & & \\
\hline مناسب الى حد مـا & $\% \vee 0, \leqslant r$ & $\cdot, r$ & r, Y & $\varepsilon r$ & - & $1 \varepsilon$ & 0 & 1. & & की \\
\hline مناسب & $\% 97, \leqslant 9$ & $\cdot, \cdot \varepsilon$ & r,^q & 00 & - & r & iv & 11 & & .q \\
\hline مناسب & $\% q \leq, v r$ & $\cdot, r_{0}$ & $r, \wedge \varepsilon$ & $0 \leqslant$ & 1 & 1 & iv & ir & & $\overline{9}$ \\
\hline مناسب & $\% q r, q \wedge$ & $\cdot, \mathrm{rA}$ & $r, \vee \wedge$ & or & 1 & $r$ & 17 & ir & & \\
\hline مناسب & $\% q \leq, \vee r$ & $\cdot, 1 \leqslant$ & $r, \wedge \varepsilon$ & $0 \leqslant$ & - & $r$ & 17 & $1 \varepsilon$ & & \\
\hline مناسب & $\% q \wedge, r \leq$ & $\cdot, \cdot r$ & r. $q \leq$ & 07 & - & 1 & 11 & 10 & & \\
\hline مناسب الى حد مـا & $\% \vee v, 19$ & $\cdot, Y Y$ & $r, r_{1}$ & $\leqslant \varepsilon$ & $\cdot$ & ir & 7 & 17 & & \\
\hline مناسب & $\% 1 \ldots$ & . & $r$ & $O V$ & . & . & 19 & IV & $E$ E & \\
\hline مناسب & $\% q \leq, v r$ & $\cdot, r_{0}$ & $r, \wedge \varepsilon$ & $0 \leqslant$ & 1 & 1 & iv & 11 & $\underline{E} \underline{E}$ & \\
\hline مناسب & $\% 94.91$ &.. $\mathrm{r}$ & r.VA & or & 1 & r & 17 & 19 & & \\
\hline مناسب & $\% q \wedge, r \leq$ & $\cdot, \cdot r$ & r. $9 \leq$ & 07 & $\cdot$ & 1 & 11 & $r$. & & \\
\hline مناسب & $\% q 4, q \wedge$ & $\cdot, I V$ & r.VA & or & $\dot{-}$ & $\varepsilon$ & 10 & YI & 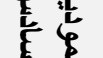 & \\
\hline مناسب & $\% \wedge q, \leqslant \vee$ & $\cdot, \leqslant 0$ & $r, 7 \wedge$ & 01 & $r$ & $r$ & 10 & $r r$ & & \\
\hline
\end{tabular}




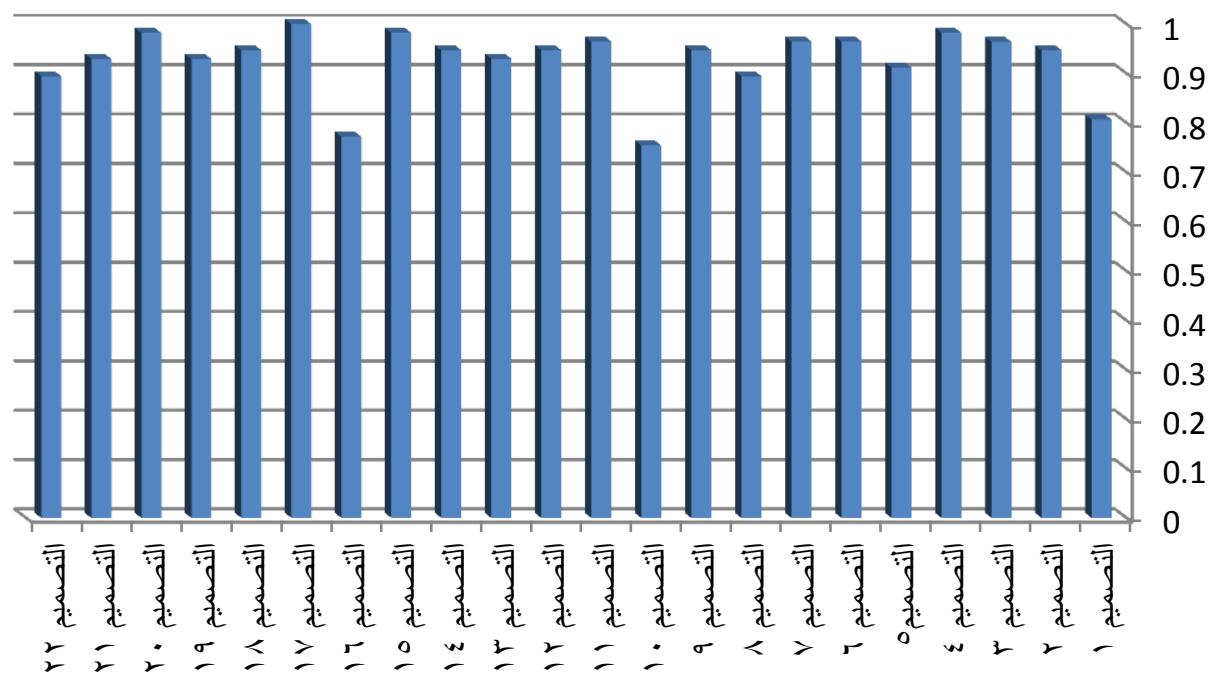

شكل ( r ) ترتيب التصميمات المقترحه وفق معاملات الجودة لأراء المتخصصين المقترحة المتخصصين لاعادة تدوير البنطلون فئتحقيق أسس التصميم.

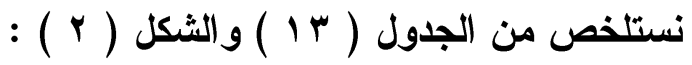

إتفاق أر اء السادة المتخصصين حول التصميمات المقترحة فى تحقيق أسس التصميم حيث نجد أن ثقييم معاملات الجودة للتصميمات المقترحة تكون مرتفعه حيث تبين أن عدد (ب. (Y)

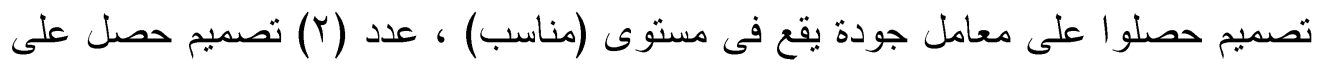
معامل جودة يقع فى مستوى (مناسب إلى حد ما) ، نز اوحت معاملات الاتفاق ما بين

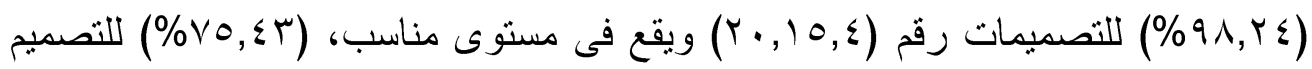
رقم (• () ويقع فى مستوى مناسب الي حد ما. مما يؤكد قدرة التصميمات المقترحة من اعادة تدوبر البنطلون فى تحقيق أسس النصمين. 


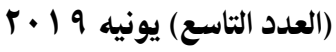

\section{المجلة العلمية لعلوم التربية النوعية}

جدول ( ؛ 1 ) تحليل التباين لاراسة معنوية الفروق بين إستجابات السادة المتخصصين على التصميمات المقترحة لاعادة تدوير البنطلون تحقيق أسس التصميم

\begin{tabular}{|c|c|c|c|c|c|c|c|}
\hline مستوى & الالالة & $\mathbf{F}$ & متوسط المربعات & المربعوع & لدرجات & مصدر & المحور الثانى \\
\hline \multirow{3}{*}{ 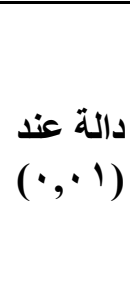 } & \multirow{3}{*}{$\cdot, \cdots$} & \multirow{3}{*}{$0, \leqslant 1 r$} & $\cdot, \wedge r r$ & $\mid V, \leq Y \leq$ & rI & التصميمات & \multirow{3}{*}{ تحقيق أسسم } \\
\hline & & & $\cdot, 10 \leqslant$ & $r, \wedge \leq r$ & एव & التصميمات داخل & \\
\hline & & & - & $\vee \wedge, r \cdot T$ & 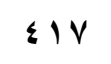 & الإجمالى & \\
\hline
\end{tabular}

نستخص من الجدول ( \& 1 ) :

وجود فروق ذات دلالة إحصائيه عند مستوى دلالة (1.,.•) بين إستجابات السادة

المتخصصين على التصميميات المقترحة فى عناصر التصميم حيث بلغت قيمة (ف) لونه با إ,0, ومستوى الدلالة أقل من مستوى المعنوية (1 ., •) ، مما يدل على وجود فروق بين التصميمات فى هذا المحور مما يؤكد تحقق الفرض الثانى.

\section{ب-النتائج المتعلقة بالفرض الثالث}

"يوجد فروق ذات دلالة إحصائية بين منوسطات أراء المحكمين على التصميمات المقترحة تحقيق الجانب الابتكارى فى توظيف الموضة متعددة الاغر اض فى إعادة تدوير البنطلون الحريمى وللتحقق من صحة هذا الفرض تم حساب المتوسط المرجح و المتوسط المئوى المرجح و الإنحر اف المعيارى لأر اء المتخصصين على التصميمات المقترحة بالنسبة لاعادة تدوير البنطلون الحريمي. 


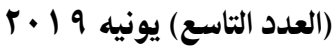

المجلة العلمية لعلوم التربية النوعية

جدول ( 10 ) المتوسط المرجح والمتوسط المئوى المرجح والإنحراف المعيارى لأراء المتخصصين حول التصميمات المقترحة من اعاد تدوير البنطلون فى تحقيق الجانب الابتكارى"

\begin{tabular}{|c|c|c|c|c|c|c|c|c|c|c|}
\hline \multirow{2}{*}{ مستوى التصميم } & \multirow{2}{*}{ المتوسط المئوى } & \multirow{2}{*}{ 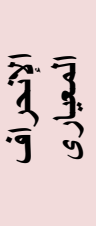 } & \multirow{2}{*}{$\begin{array}{l}\overline{3} \\
3 \\
\overline{3} \\
\overline{3}\end{array}$} & \multirow{2}{*}{$\begin{array}{l}\text { j. } \\
\text { w } \\
\frac{3}{5} \\
.5\end{array}$} & \multicolumn{3}{|c|}{ مستويات المؤشرات } & \multirow{2}{*}{ 可 } & & \multirow{2}{*}{ الثحالثر } \\
\hline & & & & & 3 & $\overline{3}$ & $\frac{3}{3}$ & & & \\
\hline مناسب & $\% q 1, r r$ & $\cdot, r$ & $r, v r$ & or & . & 0 & $1 \varepsilon$ & 1 & & \\
\hline مناسب & $\% 97, \leqslant 9$ & $\cdot, \cdot \varepsilon$ & $r, \wedge q$ & 00 & - & $r$ & iv & $r$ & & \\
\hline مناسب & $\% q \leq, \vee r$ &., $1 \leq$ & $r, \wedge \varepsilon$ & 0 & - & $r$ & 17 & $r$ & & \\
\hline مناسب & $\% q \leq, \vee r$ & $\cdot, r_{0}$ & $r, \wedge \varepsilon$ & $0 \leqslant$ & 1 & 1 & $1 \mathrm{~V}$ & $\varepsilon$ & & \\
\hline مناسب & $\% 91, r r$ & $\cdot, r$ & $r, v r$ & or & - & 0 & $1 \leq$ & 0 & & \\
\hline مناسب & $\% q \wedge, r \leq$ & $\cdot, \cdot r$ & Y. $9 \leq$ & 07 & - & 1 & 11 & 7 & & \\
\hline مناسب & $\% q \leq, v r$ & $\cdot, r_{0}$ & $r, \wedge \varepsilon$ & $0 \leq$ & 1 & 1 & IV & v & & \\
\hline مناسب & $\% 1 \ldots$ & - & $r$ & $\Delta V$ & - & - & 19 & $\Lambda$ & & \\
\hline مناسب & $\% q \leq, \vee r$ & $\cdot, 1 \leq$ & $r, \wedge \varepsilon$ & $0 \leq$ & - & $r$ & 17 & 9 & & \\
\hline مناسب & $\% 97, \leqslant 9$ & $\cdot, \cdot \varepsilon$ & $r, \wedge q$ & 00 & - & r & $1 v$ & 1. & & 7 \\
\hline مناسب & $\% 91, r r$ & $\cdot, r$ & $r, v r$ & or & - & 0 & $1 \leq$ & 11 & & 星 \\
\hline مناسب & $\% \wedge \cdot, \vee$ & $\cdot, r o$ & $r, \leqslant r$ & $\varepsilon 7$ & - & 11 & $\wedge$ & ir & p & 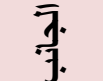 \\
\hline مناسب & $\% 9 \wedge, Y \leq$ & $\cdot, r$ & r.9ะ & 07 & - & 1 & 11 & ir & & . \\
\hline مناسب & $\% 1 \ldots$ & - & $r$ & $\Delta V$ & - & - & 19 & $1 \varepsilon$ & & y \\
\hline مناسب & $\% q \leq, \vee r$ & $\cdot, 1 \leq$ & $r, \wedge \varepsilon$ & \& & - & $r$ & 17 & 10 & & \\
\hline مناسب & $\% \wedge \cdot, \vee$ & $\cdot, r^{\circ}$ & $r, \leqslant r$ & $\leqslant 7$ & - & 11 & $\wedge$ & 17 & & \\
\hline مناسب & $\% 97, \leqslant 9$ & $\cdot, \cdot \varepsilon$ & $r, \wedge q$ & 00 & - & r & IV & iv & $E$ E & \\
\hline مناسب & $\% 91, r r$ & $\cdot, r$ & $r, v r$ & or & - & 0 & $1 \leq$ & 11 & & \\
\hline مناسب & $\% q \leq, V Y$ & $\cdot, r_{0}$ & $r, \wedge \varepsilon$ & 0 \& & 1 & 1 & iv & 19 & & \\
\hline الى حذب ماسب & $\% \vee 0, \varepsilon r$ & $\cdot, r$ & $r, r q$ & $\varepsilon r$ & - & $1 \leq$ & 0 & $r$. & $\mathcal{E} \mathbb{E}$ & \\
\hline مناسب & $\% 9 \leq, \vee r$ & $\cdot, 1 \leq$ & $r, \wedge \varepsilon$ & $0 \leq$ & - & $r$ & 17 & YI & & \\
\hline مناسب & $\% 97, \leqslant 9$ & $\cdot, \cdot \varepsilon$ & $r, \wedge q$ & 00 & - & r & iv & rr & & \\
\hline
\end{tabular}




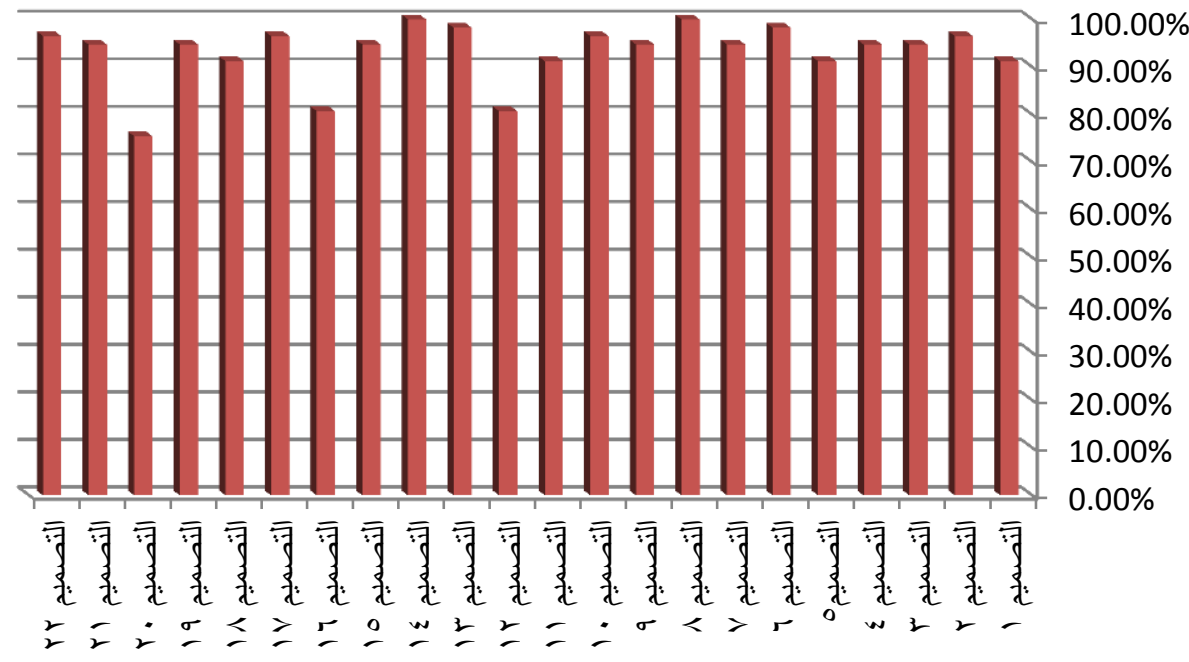

شكل ( r ) ترتيب التصميمات المقترحه وفق معاملات الجودة لأراء المتخصصين حول التصميمات المفذة من اعاد تدوير البنطلون فى تحقيق الجاتب الابتكارى مئمي

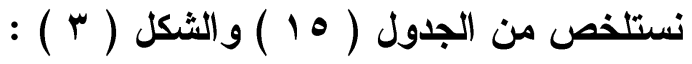
إتفاق أر اء السادة المتخصصين حول التصميمات فى تحقيق الجانب الابتكارى و مستوى كل تصميم من التصميمات نجد أن ثقييم معاملات الجودة للتصميمات المقترحة تكون مرتفعه حيث تبين أن عدد (YI) تصميمات حصلو ا على معامل جودة يقع فى مستوى لهن (مناسب)، عدد (1) تصميم حصل على معامل جودة يقع فى مستوى (مناسب إلى حد ما).

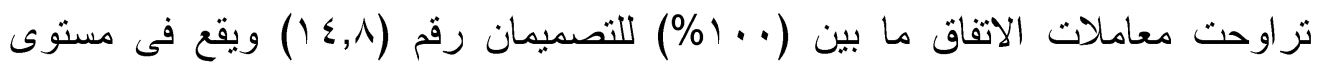

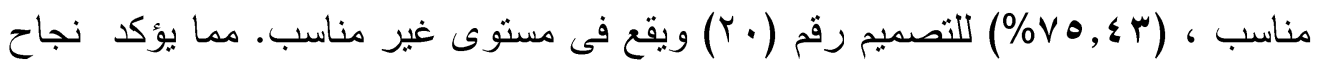
الصميمات فى تحقيق الجاتب الابتكارى. 
(العدد التاسع) يونيه 9 | + F

جدول ( 17 ) ) تحليل التباين لدراسة معنوية الفروق بين إستجابات السادة المتخصصين

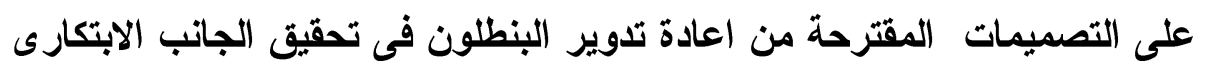

\begin{tabular}{|c|c|c|c|c|c|c|c|}
\hline مستوي & الالالة & $\mathbf{F}$ & متوسط المربعات & المربعوات & الحرية & مصدر التباين & المحور الثالث \\
\hline \multirow{3}{*}{ 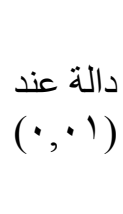 } & \multirow{3}{*}{,$\cdots$} & \multirow{3}{*}{$0, \leqslant 11$} & $\cdot, 100$ & 10,107 & Y) & بين التصميمات & \multirow{3}{*}{ تحقيق الجانب } \\
\hline & & & $\cdot, 1 \leq$. & תוT & r97 & داخل التصميمات & \\
\hline & & & - & VI, Ir. & $\varepsilon 1 V$ & الإجمالى & \\
\hline
\end{tabular}

نستلخص من الجدول ( 14 ) : وجود فروف ذات دلالة إحصائيه عند مستوى دلالة

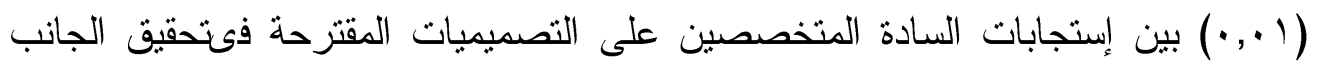

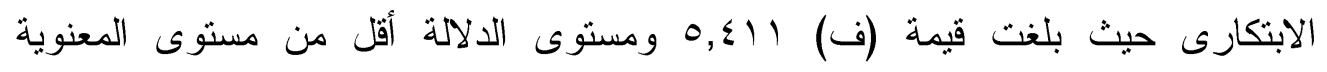

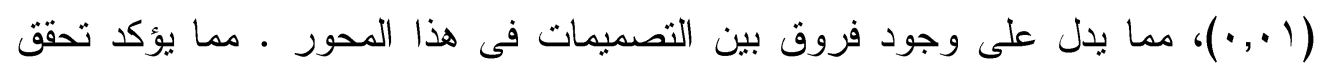

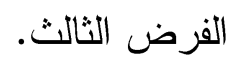
؛ - النتائج المتعلقة بالفرض الرضابع يوجد فروق ذات دلالة إحصائية بين متوسطات أراء المحكمين على التصميمات المقترحة فى تحقق الجانب الوظيفى فى توظيف الموضة متعددة الاغر اض فى إعادة تدوير البنطلون

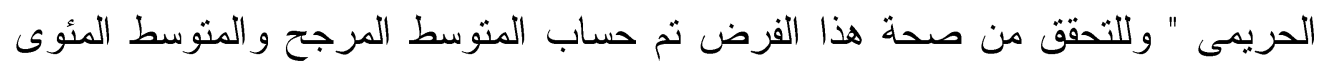
المرجح والإنحر اف المعيارى لأراء المتخصصين للتصميمات المقترحة بالنسبة لاعادة

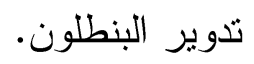


جدول( IV ) يوضح المتوسط المرجح والمتوسط المئوى المرجح والإنحر اف المعيارى لأراء المتخصصين للتصميمات المنفذة من اعادة تدوير البنطلون فى تحقق الجاتب

الوظيفى.

\begin{tabular}{|c|c|c|c|c|c|c|c|c|c|c|}
\hline \multirow[b]{2}{*}{ التصميم } & \multirow[b]{2}{*}{ 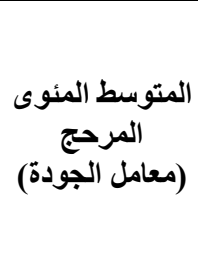 } & \multirow{2}{*}{$\begin{array}{l}\overline{3} \\
\bar{y} \\
\overline{3} \\
\overline{3}\end{array}$} & \multirow[b]{2}{*}{ 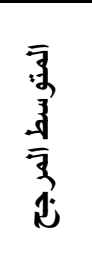 } & \multirow[b]{2}{*}{ 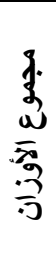 } & \multicolumn{3}{|c|}{ مستويات المؤشرات } & \multirow[b]{2}{*}{ 司 } & & \multirow[b]{2}{*}{ الرابع } \\
\hline & & & & & .9. & $\begin{array}{l}-\frac{1}{3} \\
\overline{3} \\
4 \\
3 \\
3\end{array}$ & 争. & & & \\
\hline مناسب & $\%^{\wedge \wedge} . \& \vee$ & •, Yr & ז, ג & 01 & . & 9 & ir & 1 & C. & \multirow{22}{*}{$\begin{array}{l}\text { 过 } \\
\bar{y} \\
\bar{y} \\
\overline{3}\end{array}$} \\
\hline مناسب & $\% q 4, q \wedge$ & $\cdot, \mathrm{lv}$ & r.v^ & r & . & $\varepsilon$ & 10 & $r$ & 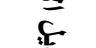 & \\
\hline مناسب & $\%$ \%५.q1 & $\cdot .^{M \Lambda}$ & ५.VA & rه & 1 & $r$ & 17 & $r$ & & \\
\hline مناسب & $\% q 1, r r$ & $\cdot, r$ & $r, V \mu$ & Or & . & - & $1 \leqslant$ & $\varepsilon$ & & \\
\hline مناسب & $\% q \varepsilon, \vee r$ & • & $r, \Lambda \varepsilon$ & \& & . & $r$ & 17 & 0 & & \\
\hline مناسب & $\% 94,9 \wedge$ & $\cdot, \mathrm{lv}$ & r.VA & ب & $\cdot$ & $\varepsilon$ & 10 & 1 & $\frac{\pi}{6}$ & \\
\hline مناسب & $\% \wedge$ $\%$ \& & $\cdot, r \mu$ & $r, 4$ & 01 & . & 9 & ir & $\mathrm{v}$ & $\underline{\underline{e}}$ & \\
\hline مناسب & $\% q \wedge, r \leqslant$ & $\cdot, \cdot r$ & T.q & 04 & . & 1 & 11 & $\wedge$ & & \\
\hline مناسب & $\% 94.91$ & $\therefore$ r & Y.VA & ب & 1 & $r$ & 17 & 9 & $E$ & \\
\hline مناسب & $\%^{\wedge} \cdot,,^{\vee}$ & r, & $r, \leqslant r$ & $\leq 4$ & . & 11 & $\wedge$ & 1. & 5 & \\
\hline مناسب الى حلى & $\% \vee v, 19$ & •, r & $r, r)$ & « & $\cdot$ & ir & 1 & 11 & & \\
\hline مناسب & $\% 97, \leqslant 9$ & • \& & $r, \wedge q$ & $\infty$ & . & $r$ & iv & ir & & \\
\hline مناسب & $\%{ }^{q}, r^{r}$ & $\cdot, r$ & $r, \vee r$ & or & . & 0 & $1 \leqslant$ & 14 & $\underline{\underline{E}}$ & \\
\hline مناسب & $\% 97, \leqslant 9$ & $\cdot$ & $r, \wedge q$ & $\infty$ & . & $r$ & iv & $1 \varepsilon$ & $\frac{E}{6}$ & \\
\hline مناسب & 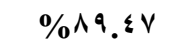 & •, r & r, & 01 & . & 1 & ir & 10 & & \\
\hline هناسب الى ملى & $\% \vee v, 19$ & •, r & r, & ๕ & . & ir & 1 & 17 & & \\
\hline مناسب & $\% 9 \varepsilon, \vee r$ & • & $r, \wedge \varepsilon$ & \& & . & $r$ & 17 & iv & E: & \\
\hline مناسب & $\%{ }^{q}, r^{r}$ & $\cdot, r$ & $r, V r$ & Or & $\cdot$ & 0 & $1 \leqslant$ & 11 & 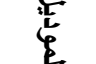 & \\
\hline مناسب & $\% 9 \wedge, r \leqslant$ & $\cdot, \cdot r$ & r.q & צ & . & 1 & in & 19 & & \\
\hline مناسب & $\%^{\wedge} \cdot, \nu$ & $\cdot, r_{0}$ & $r, \leqslant r$ & $\leq 4$ & . & 11 & $\wedge$ & r. & & \\
\hline مناسب & $\% q \neg, q \wedge$ & $\cdot, \mathrm{IV}$ & r.VA & ro & $\cdot$ & $\varepsilon$ & 10 & r & $\frac{E}{5}$ & \\
\hline مناسب & $\%^{\wedge \uparrow .} \leqslant \vee$ & $\cdot$, r r & $r, T \Lambda$ & 01 & . & 7 & ir & rr & & \\
\hline
\end{tabular}




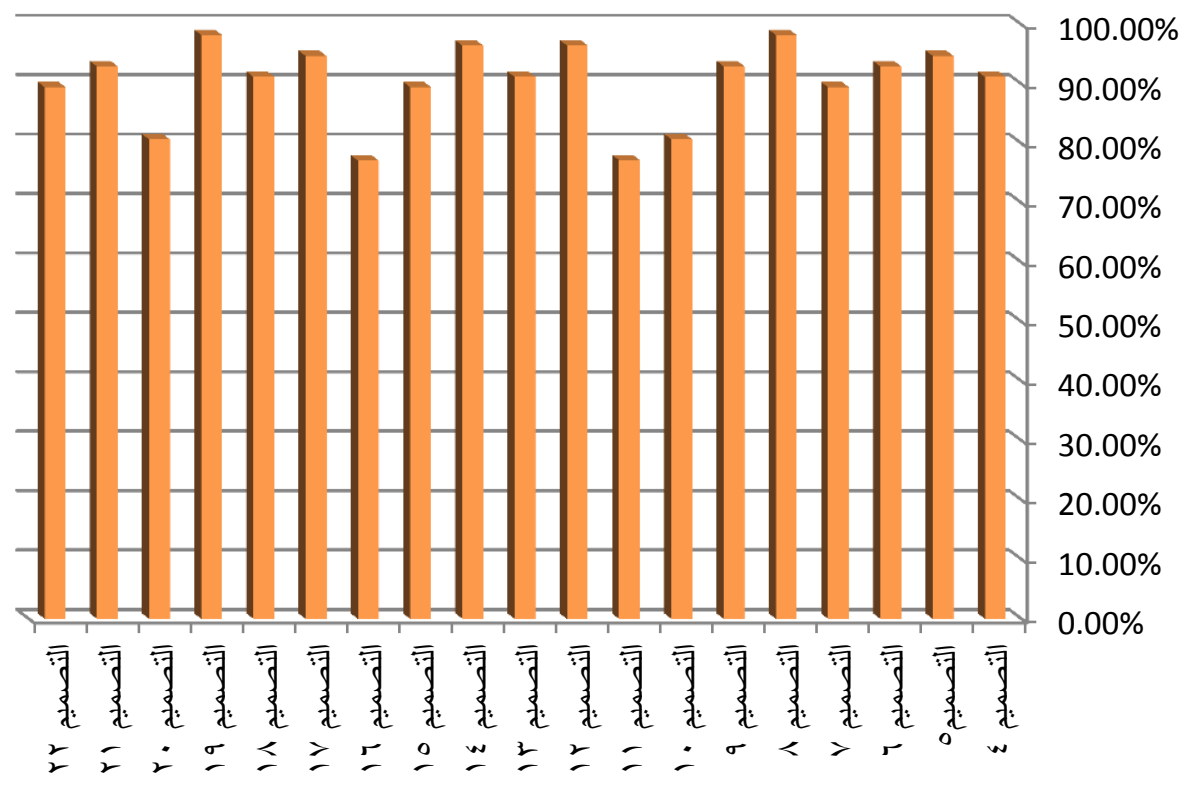

شكل ( ع ) ترتيب التصميمات المقترحه وفق معاملات الجودة لأراء المتخصصين التصميمات المنفذة م اعاد تدوير البنطلون فى تحقق الجاتب الوظيفى.

نستلخص من الجدول( IV ) و الثكل ( ع ) : اتفاق أر اء السادة المتخصصين التصميمات فى تحقق الجانب الوظيفى.ومستوى كل تصميم

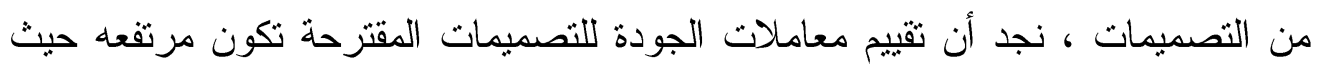
تبين أن عدد (·r) حصلو ا على معامل جودة يقع فى مستوى (مناسب) ، عدد (Y) تصميم حصل على معامل جودة يقع فى مستوى (مناسب إلى حد ما ) .

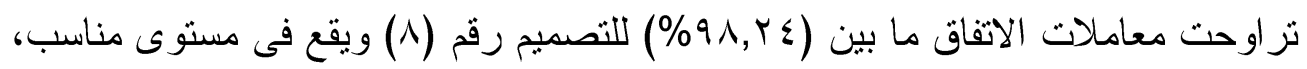
(\%VV,19)

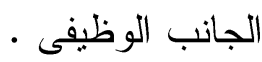




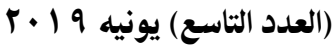

\section{المجلة العلمية لعلوم التربية النوعية}

جدول ( 1 ( ) ) تعليل التباين لاراسة معنوية الفروق بين استجابات السادة المتخصصين على التصميمات المنفذ من اعادة تدوير البنطلون فى تحقق الجاتب الوظيفى.

\begin{tabular}{|c|c|c|c|c|c|c|c|}
\hline الدلاحة & الدلالة & $\mathbf{F}$ & متوسط المربعات & المربعات & الحرية & مصدر التباين & المحور الرابع \\
\hline \multirow{3}{*}{ 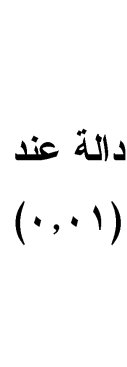 } & \multirow{3}{*}{$\cdot, \ldots$} & \multirow{3}{*}{$\varepsilon, \cdot v}$. & $\cdot, \vee \vee \wedge$ & 19,rro & ri & التصميمات & \multirow{3}{*}{ تحقى الجانب } \\
\hline & & & $\cdot, 191$ & $V_{0, T \wedge \varepsilon}$ & P97 & التصميمات & \\
\hline & & & - & $94, .19$ & $\{1 V$ & الإجمالي & \\
\hline
\end{tabular}

نستخلص من الجدول ( 11 ) : وجود فروق ذات دلالة إحصائيه عند مستوى دلالة (1 (..) بين إستجابات السادة المتخصصين على التصميميات المقترحة ملائمة الخامة

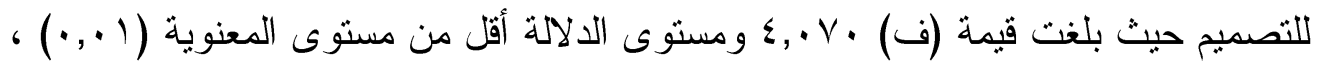
مما يدل على وجود فروق بين التصميمات فى هذا المحور . مما يؤكد تحقق الفرض الر ابع.

النتائج المتعلقة بالفرض الخامس

يوجد فروق ذات دلالة إحصائية بين متوسطات أراء المحكمين على التصميمات المقترحة فى نوظيف الموضة متعددة الاغر اض فى إعادة تدوير البنطلون الحريمى " اعادة تدوير

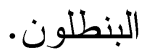




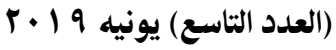

المجلة العلمية لعلوم التربية النوعية

جدول ( 9 ( ) المتوسط المرجح والمتوسط المئوى المرجح وترتيب التصميمات المنفذة من اعادة تدوير البنطلون وتقديرها طبقاً لإستجابات السادة المتخصصين لجميع المحاور

\begin{tabular}{|c|c|c|c|c|c|c|c|c|c|c|}
\hline \multirow{2}{*}{ مستوى التصميم } & \multirow{2}{*}{ التصميمات } & \multirow{2}{*}{ المرائوى المودج } & \multirow{2}{*}{$\begin{array}{l}\frac{7}{3} \\
\frac{9}{9} \\
\overline{3} \\
9 \\
9 \\
y\end{array}$} & \multirow{2}{*}{$\begin{array}{l}\overline{3} \\
3 \\
3 \\
\overline{3} \\
3 \\
13\end{array}$} & \multirow{2}{*}{ 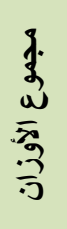 } & \multicolumn{3}{|c|}{ مستويات المؤشرات } & \multirow{2}{*}{ التصميم } & \\
\hline & & & & & & - $q_{1}=\frac{3}{3}$ & 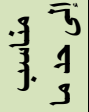 & .3. & & \\
\hline مناسب & عشرى & $\% \wedge q, \vee$ & $\cdot, r_{1}$ & $r, T V$ & $r \cdot r$ & . & $r r$ & or & 1 & \multirow{3}{*}{$\underset{\underline{\underline{E}}}{\underline{\underline{E}}}$} \\
\hline مناسب & الرابع & $\% 90,1$ & $\cdot, 1 r$ & $r, \wedge 0$ & rIV & . & 11 & 70 & $r$ & \\
\hline مناسب & السابع & $\% 9 r, \varepsilon$ & $\cdot, 11$ & $r, \wedge$ & rir & 1 & ir & it & $r$ & \\
\hline مناسب & السادس & $\% 9 r, \wedge$ & $\cdot, 1 \mathrm{~V}$ & $r, \wedge 1$ & YIs & 1 & ir & Tr & $\varepsilon$ & \multirow{4}{*}{$\begin{array}{l}E \\
E \\
E \\
E \\
E \\
E\end{array}$} \\
\hline مناسب & الثامن & $\% q r, q$ & $\cdot, 17$ & $r, v \wedge$ & rIr & . & 17 & 7. & 0 & \\
\hline مناسب & الثانى & $\% 94 . \varepsilon$ & $\cdot, \cdot 1$ & $r, \wedge q$ & ו & . & $\wedge$ & 91 & 7 & \\
\hline مناسب & الخامس & $\% q \varepsilon, r$ & $\cdot, \mathrm{IV}$ & $r, \wedge r$ & rio & 1 & 11 & $T \leq$ & v & \\
\hline مناسب & الثالث & $\% 90,7$ & $\cdot, r 1$ & $r, \wedge \mathrm{T}$ & rin & $\cdot$ & 1. & 79 & $\Lambda$ & \multirow{4}{*}{$\begin{array}{l}\underline{E} \\
\underline{E} \\
\underline{E} \\
\underline{E} \\
\underline{E}\end{array}$} \\
\hline مناسب & الخامس & $\% q \leq, r$ & $\cdot, 1 \mathrm{~V}$ & $r, \wedge r$ & rio & 1 & 11 & $T \varepsilon$ & 9 & \\
\hline مناسب & الثالث عشر & $\% \wedge \vee . r$ & $\cdot, r r$ & $r, 71$ & 199 & - & rq & $\varepsilon V$ & 1. & \\
\hline مناسب & العاشر & $\% q \cdot, v$ & $\cdot, r$ & $r, v r$ & $r \cdot v$ & . & r & $\Delta 0$ & 11 & \\
\hline مناسب & الثانى عشر & $\% \%^{\wedge 9}$ & $\cdot, r_{0}$ & $r, q$ & $r \cdot r$ & 1 & $r r$ & Or & ir & \multirow{4}{*}{$\begin{array}{l}\underline{\underline{c}} \\
\underline{\underline{E}} \\
\underline{\underline{E}} \\
\underline{E}\end{array}$} \\
\hline مناسب & الرابع(م) & $\% 90,1$ & $\cdot, 10$ & $r, \wedge 0$ & riv & 1 & 9 & 74 & ir & \\
\hline مناسب & الاول & $\% 97,9$ & $\cdot, \cdot 1$ & $r, q$ & rr & . & v & 79 & $1 \varepsilon$ & \\
\hline مناسب & الخامس(م) & $\% q \leq, r$ & $\cdot, 1 \varepsilon$ & $r, \wedge r$ & rio & . & ir & rT & 10 & \\
\hline مناسب & الخامس & $\% \wedge r$ & $\cdot, r_{0}$ & $r, \leqslant \uparrow$ & IAv & . & $\leqslant 1$ & ro & 17 & \multirow{4}{*}{$\begin{array}{l}\underline{E} \\
\underline{E} \\
\underline{E} \\
\underline{E} \\
\underline{E} \\
\underline{E}\end{array}$} \\
\hline مناسب & الثانى(م) & $\% 97, \varepsilon$ & $\cdot,+1$ & $r, \wedge q$ & $r r$. & - & $\wedge$ & 71 & IV & \\
\hline مناسب & التاسع & $\% 9 r, 1$ & $\cdot, r$ & $r, v r$ & r. & 1 & 17 & 09 & 11 & \\
\hline مناسب & التاسع (م) & $\% q r, 1$ & $\cdot, r r$ & $r, \vee\urcorner$ & ri. & r & $1 \varepsilon$ & 7. & 19 & \\
\hline مناسب & الرابع عشر & $\% \wedge \varphi^{\wedge}, \bullet$ & $\cdot, r \varepsilon$ & $Y, 0 Y$ & 190 & . & $r r$ & $\varepsilon r$ & $r \cdot$ & \multirow{3}{*}{$\begin{array}{l}E \\
E \\
E \\
E\end{array}$} \\
\hline مناسب & الرابع (م) & $\% 90,1$ & $\cdot, 1 r$ & $r, \wedge 0$ & riv & · & 11 & 90 & rI & \\
\hline مناسب & الثامن (م) & $\% q r, q$ & $\cdot, r r$ & $r, \vee \wedge$ & rir & r & ir & rי & $r r$ & \\
\hline
\end{tabular}




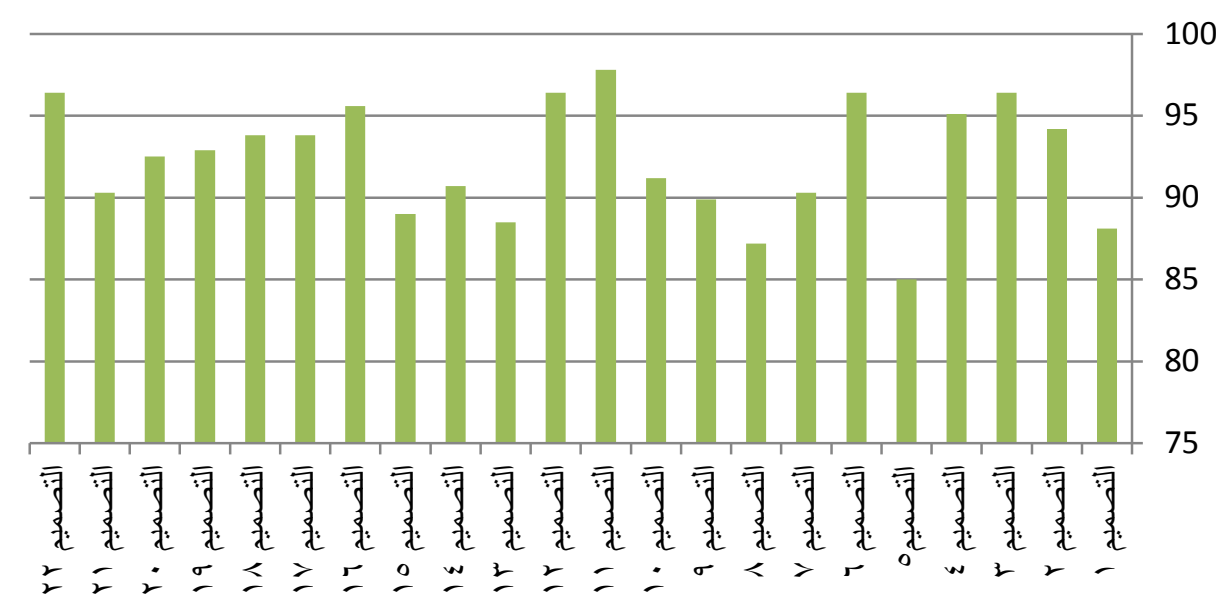

شكل ( • ) وترتيب التصميمات المنفذ من اعادة تدوير البنطلون وتقديرها طبقاً لإستجابات السادة المتخصصين لجميع المحاور

نستلخص من الجدول ( 19 ) و الشكل ( 0 ) :

ترثيب التصميمات المقترحة وفق إستجابات السادة المتخصصين بالنسبة لجميع المحاورفقد

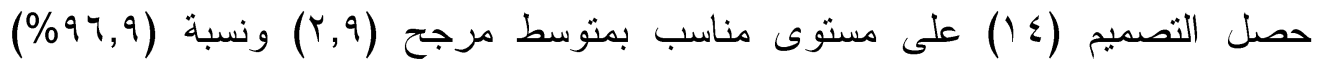
وترنيبه الأول ، يليه التصميمان (Y,T) (IV,T) حصلا على مستوى مناسب بمنوسط مرجح

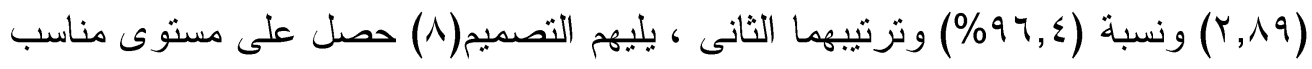

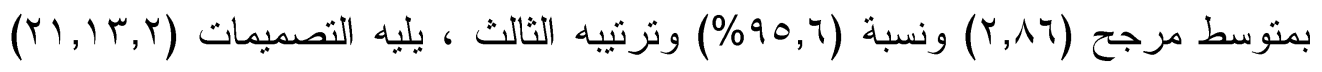

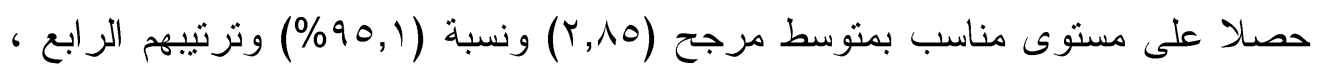

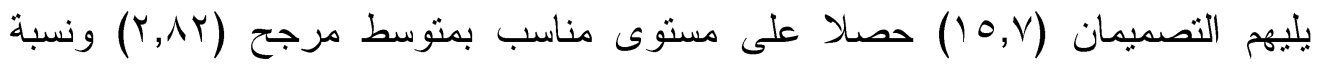

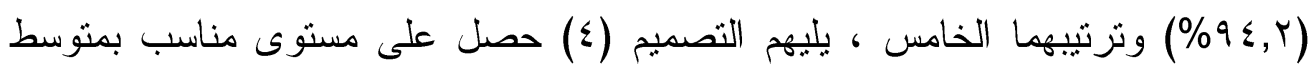

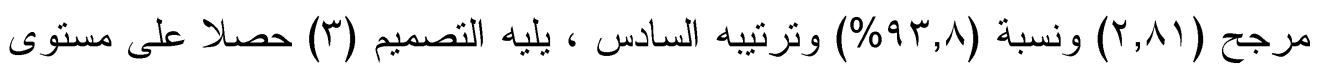

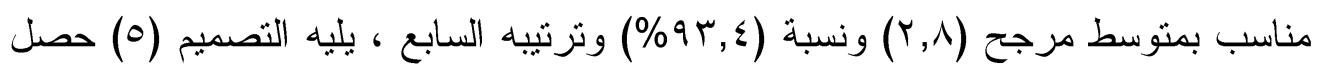

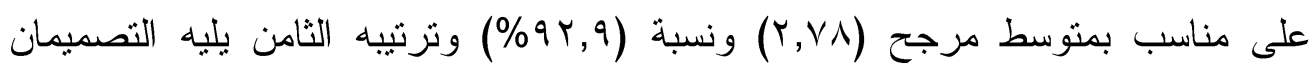

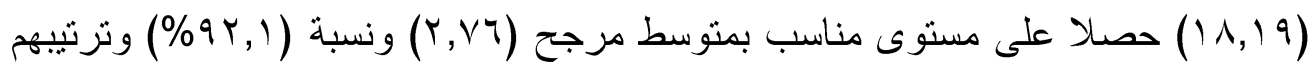

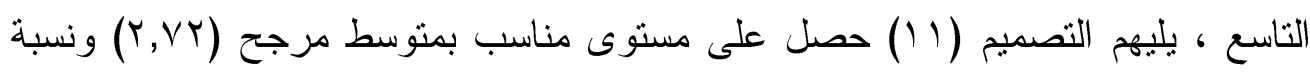

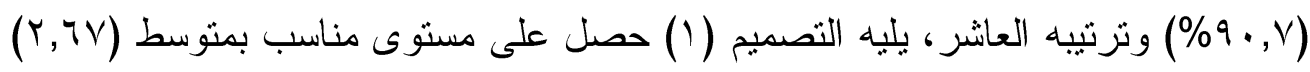

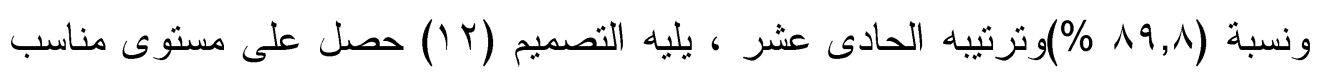




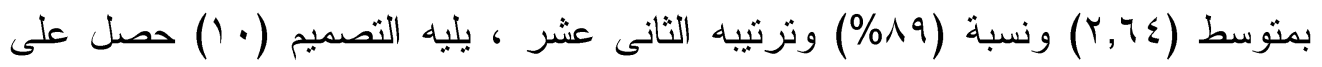

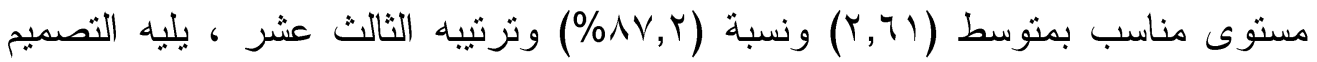

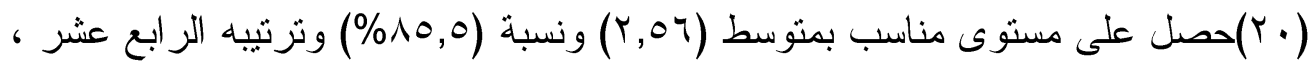

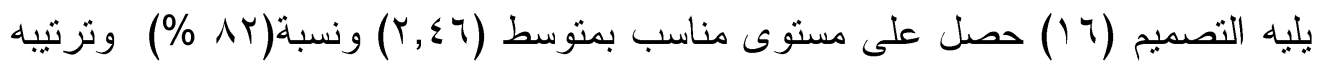
الخامس عشر .

جدول ( • r ) تحليل التباين لارسة معنوية الفروق بين إستجابات السادة المتخصصين على التصميميات المنفذ من اعادة تدوير البنطلون وتقديرها طبقاً لإستجابات السادة لكل محاور الاستبيان

\begin{tabular}{|c|c|c|c|c|c|c|c|}
\hline مستولة & الدلالة & $\mathbf{F}$ & متوبطات & المربعوت & الرجية & مصدر التباين & الإستبيان \\
\hline \multirow{3}{*}{ 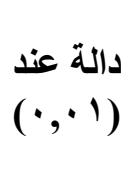 } & \multirow{3}{*}{$\cdot, \cdots$} & \multirow{3}{*}{ 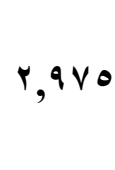 } & • & $7,7 \vee 1$ & Y & بين التصميمات & \\
\hline & & & $\cdot, 1 \cdot v$ & $\varepsilon r, r \wedge q$ & एव & داخل التصميمات & \\
\hline & & & - & $\{\wedge, 97)$ & $\varepsilon \mid V$ & الإجمالى & \\
\hline
\end{tabular}

نستلخص من الجدول ( • r ) : يوجد فروق ذات دلالة إحصائيه عند مستوى دلالة (1 ·, ·)

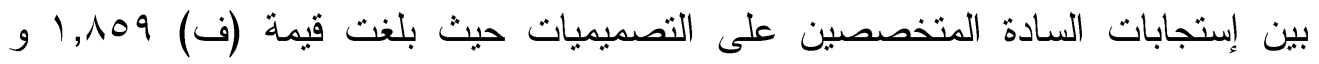
مستوى الدلالة أقل من مستوى المعنوية (1.,.·) ، مما بدل على وجود فروق بين التصميمات فى الإستبيان ككل. ملخص النتائج النتائج المتعلقة بالفرض الاول - وجود فروق ذات دلالة إحصائيه عند مستوى دلالة (1 +..) بين إستجابات السادة

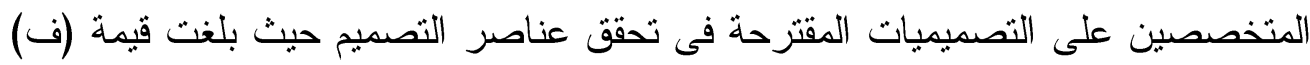

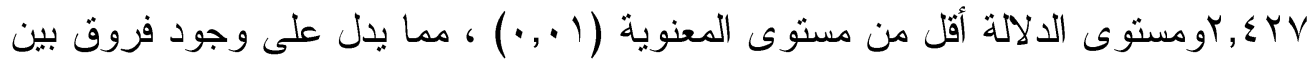

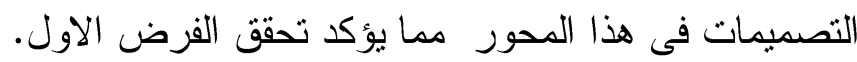
r) النتائج المتعلقة بالفرض الثى هداني: كوجود فروق ذات دلالة إحصائيه عند مستوى دلالة (1.,.) بين إستجابات السادة المتخصصين على التصميميات المقترحة فى عناصر التصميم حيث بلغت قيمة (ف) دله دله 
با إ,ه ومستوى الدلالة أقل من مستوى المعنوية (1 .,. ) ، مما يدل على وجود فروق بين التصميمات فى هذا المحور مما يؤكد تحقق الفرض الثانى.

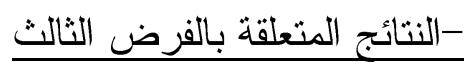
وجود فروق ذات دلالة إحصائيه عند مستوى دلالة (1.,.) بين إستجابات السادة المتخصصين على التصميميات المقترحة فى تحقيق الجانب الابتكارى حيث بلغت قيمة دله دله

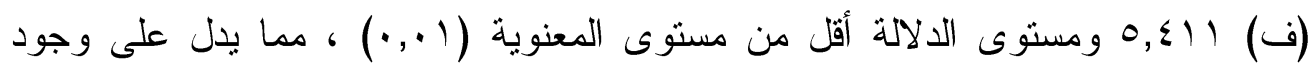
فروق بين التصميمات فى هذا المحور ـ مما يؤكد تحقق الفرض الثالث. - النتائج المتعلقة بالفرض الر ابع - وجود فروق ذات دلالة إحصائيه عند مستوى دلالة (1 +..) بين إستجابات السادة

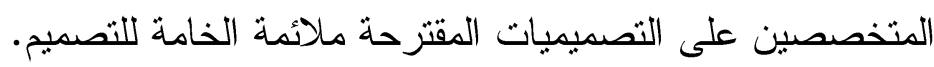

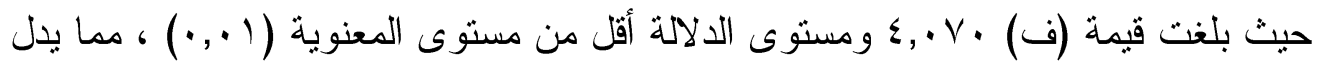
على وجود فروق بين التصميمات فى هذا المحور ـ مما يؤكد تحقق الفرض الر ابع. ترتيب التصميمات المقترحة وفق إستجابات السادة المتخصصين بالنسبة لجميع المحاورفقد

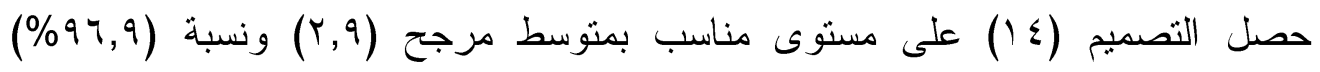

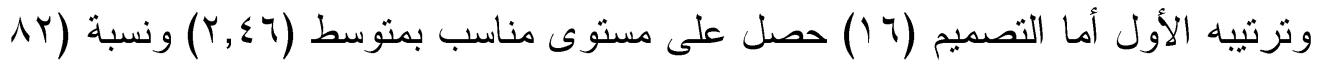
\%) وترثنبه الخامس عشر (الأخير). يوجد فروق ذات دلالة إحصائيه عند مستوى دلالة (1.,.•) بين إستجابات السادة

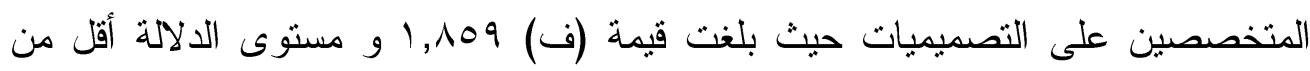
مستوى المعنوية (1 ...) ، مما يدل على وجود فروف بين التصميمات فى الإستبيان ككل. التوصبات:

تطبيق إتجاة الموضة متعددة الأغر اض فى إعادة تدوير الملابس و المفروشات وجعلها نو اة لصناعات صغيرة ومشرو عات ريادة الأعمال.

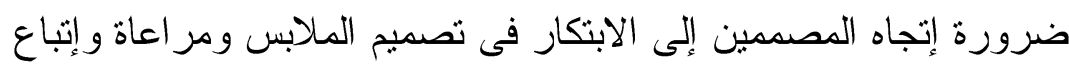

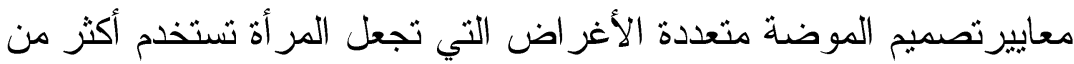

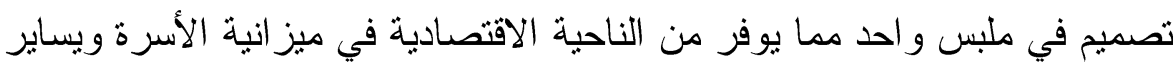
خطوط الموضة. 


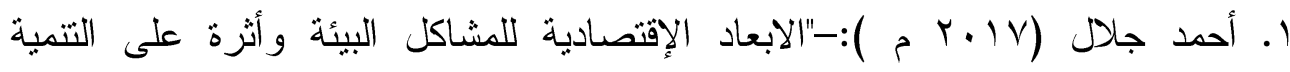

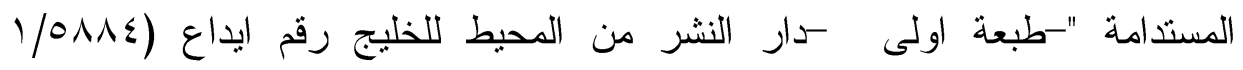
$(r \cdot) \mathrm{V})$

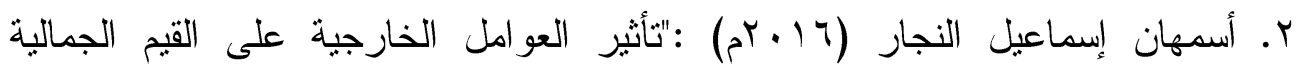

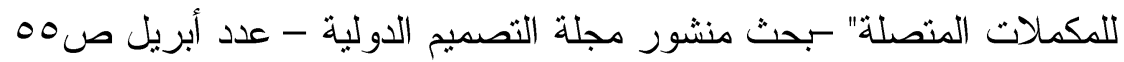

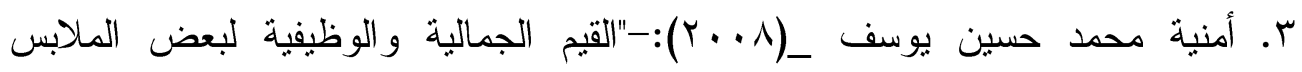

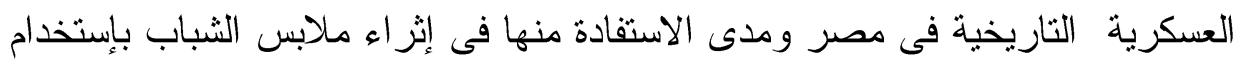

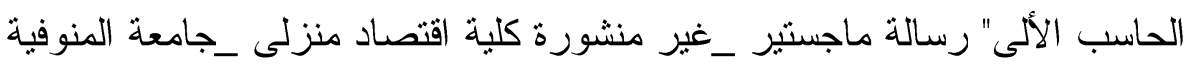

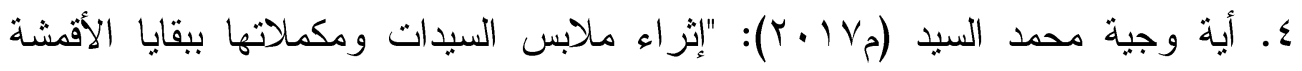
بإستخدام أسلوب فن لف الورق الملون" سرسالة ماجستير -كلية لأقتصاد المنزلى جامعة المنوفية

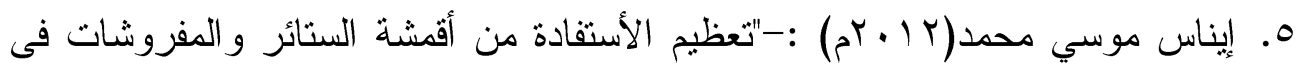

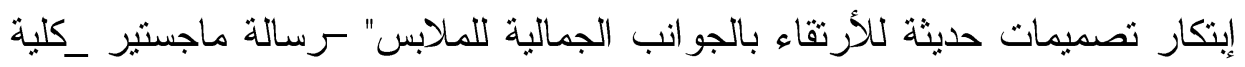
اقتصاد منزلى _جامعة المنوفية T. إيهاب فاضل أبو موسى (1 . . rم) :تصميم الأزياء - الطبعة الثالثة -ـدار الحسين للطباعة و النشر

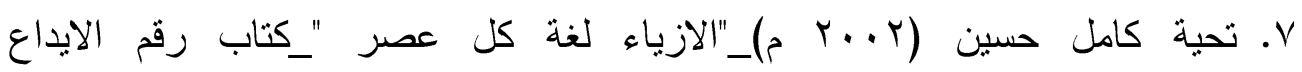
إن

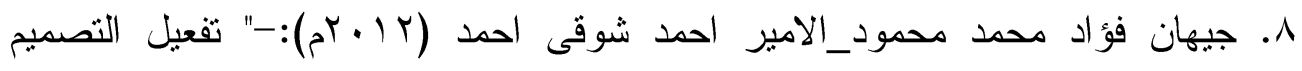

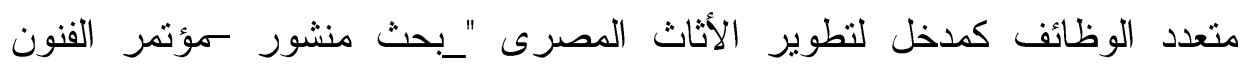

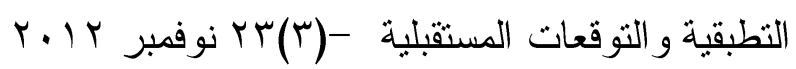

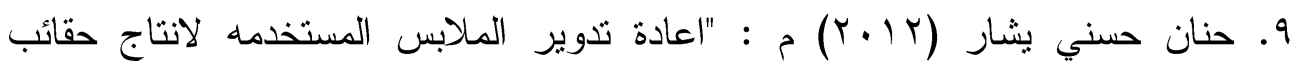

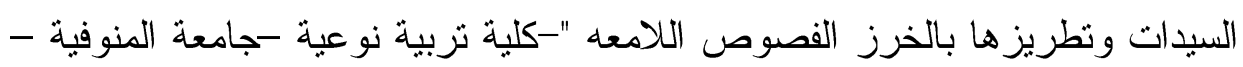

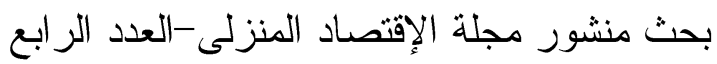

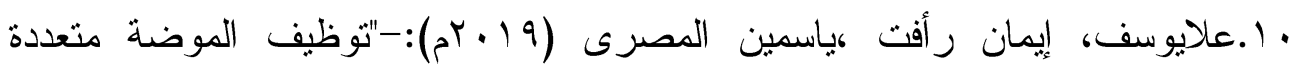

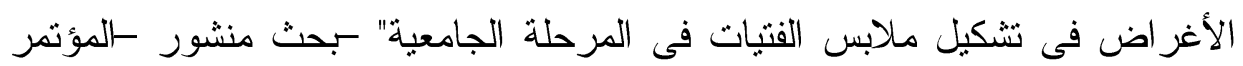

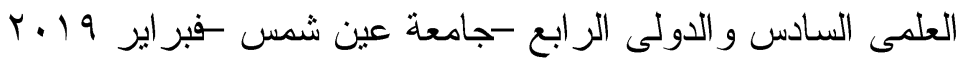




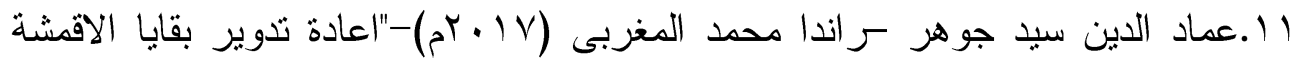
كمدخل لزخرفة ملابس الاطفال ماقبل المدرسة" _بحث منشور _مجلة التصميم الدولية

$$
\text { Y.IV اغسطس }
$$

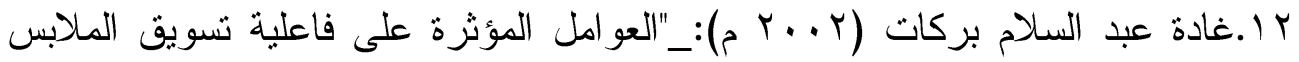

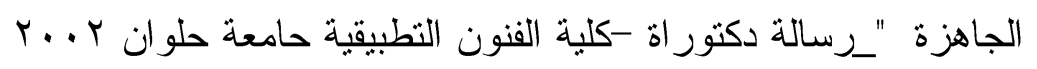

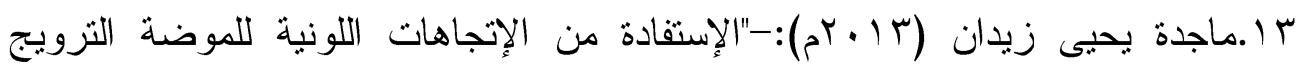

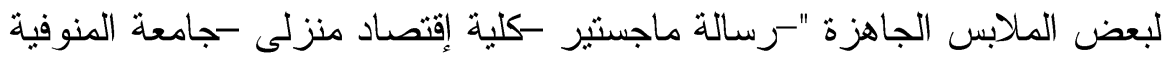

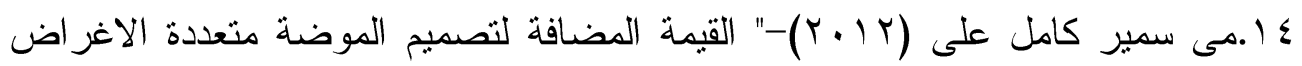

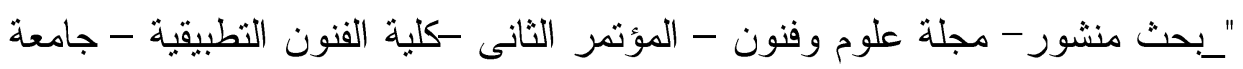

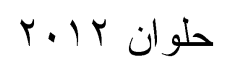

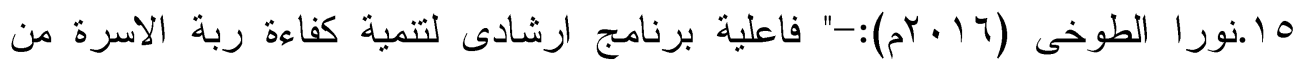

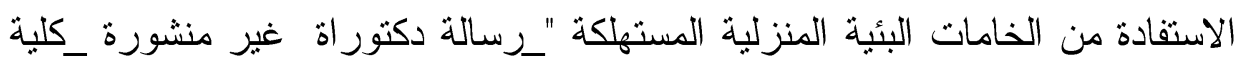

$$
\text { الاقتصاد منزلى _جامعة المنوفية }
$$

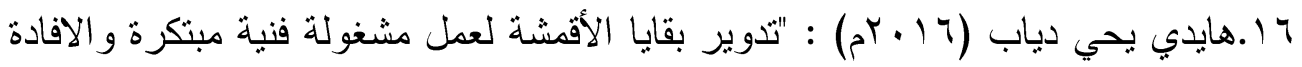

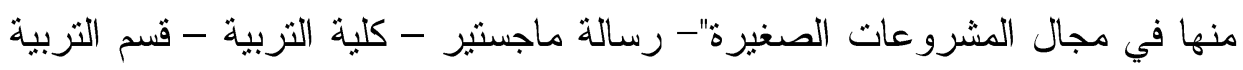
الفنية - جامعة المنيا

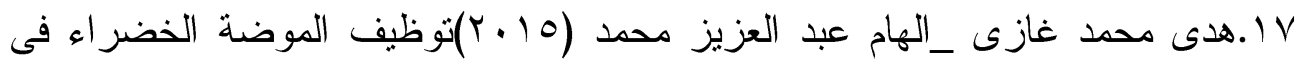

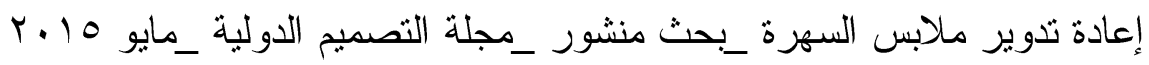

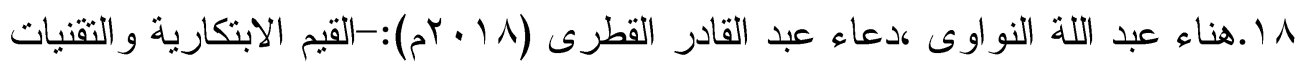

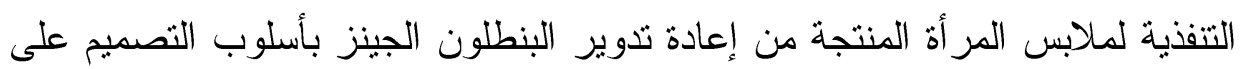

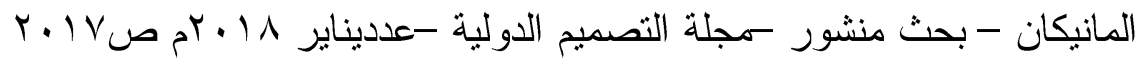

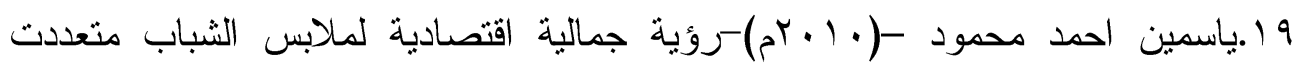
الاستخدام من خلال اسلوب من خلال اسلوب التشكيل على المانيكان -كلية تربية

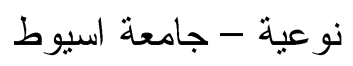

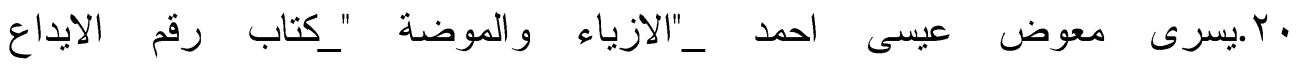

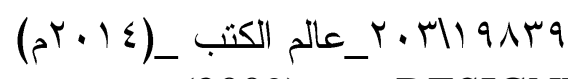

\section{J. Cunha, A. CBroega (2009)_DESIGNING} MULTIFUNCTIONAL TEXTILE FASHION PRODUCTSUniversity of Minho, School of Engineering, Department of Textile Engineering -26-28 May, 2009 Đzmir, Turkey /https://www.travelfashiongirl.com/the-top-5-convertible-travel-dresses 